\title{
INCENTIVES AND THE EFFECTS OF PUBLICATION LAGS ON LIFE CYCLE RESEARCH PRODUCTIVITY IN ECONOMICS
}

\author{
John P. Conley \\ Mario J. Crucini \\ Robert A. Driskill \\ Ali Sina Onder \\ Working Paper 17043 \\ http://www.nber.org/papers/w17043 \\ NATIONAL BUREAU OF ECONOMIC RESEARCH \\ 1050 Massachusetts Avenue \\ Cambridge, MA 02138 \\ May 2011
}

We wish to thank John Siegfried and the AEA for making JEL publication data available to us, Jonathan Lee and Peter Kozciuk for excellent research assistance. We thank Andreea Mitrut, Laurent Simula, and seminar participants at Vanderbilt University, Uppsala University and University of Gothenburg for helpful comments. We take responsibility for any errors that remain. The views expressed herein are those of the authors and do not necessarily reflect the views of the National Bureau of Economic Research.

NBER working papers are circulated for discussion and comment purposes. They have not been peerreviewed or been subject to the review by the NBER Board of Directors that accompanies official NBER publications.

(C) 2011 by John P. Conley, Mario J. Crucini, Robert A. Driskill, and Ali Sina Onder. All rights reserved. Short sections of text, not to exceed two paragraphs, may be quoted without explicit permission provided that full credit, including $(\mathcal{C}$ notice, is given to the source. 
Incentives and the Effects of Publication Lags on Life Cycle Research Productivity in Economics John P. Conley, Mario J. Crucini, Robert A. Driskill, and Ali Sina Onder

NBER Working Paper No. 17043

May 2011, Revised November 2011

JEL No. A11,J0,J11,J24

\begin{abstract}
$\underline{\text { ABSTRACT }}$
We investigate how increases in publication delays have affected the life-cycle of publications of recent Ph.D. graduates in economics. We construct a panel dataset of 14,271 individuals who were awarded Ph.D.s between 1986 and 2000 in US and Canadian economics departments. For this population of scholars, we amass complete records of publications in peer reviewed journals listed in the JEL (a total of 368,672 observations). We find evidence of significantly diminished productivity in recent relative to earlier cohorts when productivity of an individual is measured by the number of AER equivalent publications. Diminished productivity is less evident when number of AER equivalent pages is used instead. Our findings are consistent with earlier empirical findings of increasing editorial delays, decreasing acceptance rates at journals, and a trend toward longer manuscripts. This decline in productivity is evident in both graduates of top thirty and non-top thirty ranked economics departments and may have important implications for what should constitute a tenurable record. We also find that the research rankings of the faculty do not line up with the research quality of their students in many cases.
\end{abstract}

John P. Conley

Department of Economics

Vanderbilt University

401 Calhoun Hall

Nashville, TN 27235

j.p.conley@vanderbilt.edu

Mario J. Crucini

Department of Economics

Vanderbilt University

Box 1819 Station B

Nashville, TN 37235-1819

and NBER

mario.j.crucini@vanderbilt.edu
Robert A. Driskill

Vanderbilt University

robert.a.driskill@vanderbilt.edu

Ali Sina Onder

Department of Economics and

Uppsala Center for Fiscal Studies

Uppsala University

alisina.onder@nek.uu.se 


\section{Introduction}

Ellison (2002) documents that the time an economics paper typically spends at a given journal between submission and publication has more than doubled over the last thirty or so years. As Ellison notes, this has important implications:

"The change in the publication process affects the economics profession in a number of ways: it affects the timeliness of journals, the readability and completeness of papers, the evaluation of junior faculty, and so forth." (Ellison 2002 p. 948)

While all of these effects are important, the stakes may be highest when it comes to the evaluation of junior faculty. One would expect that, ceteris paribus, increased publication lags would make it more difficult for members of recent cohorts to produce as long a curriculum vitae in six years as earlier cohorts (the usual time that tenure decision is made). If institutions do not internalize the effect of the new publishing environment, then fewer junior faculty will receive tenure than in the past. At an individual level, the cost of not gaining tenure is obviously significant. However, the costs are also significant for the profession at large. Failure to promote qualified scholars leads to more frequent, costly searches by departments for new faculty and the discouragement and exit of qualified scholars who would otherwise enrich the stock of economic research.

This notwithstanding, gaining tenure is a powerful incentive. It certainly might be the case that more recent Ph.D.s respond to the new environment by working harder or smarter. While this would impose costs on junior faculty, the increased effort might partly or wholly offset longer publication lags. Thus, the question of whether or not there is an "Ellison Effect" on CVs is ultimately empirical.

In this paper, we begin by demonstrating the plausibility and potential magnitude of the Ellison Effect in a simple model of research production and publication calibrated with what we believe are plausible parameter values. We find that increasing publication delay from one period to two periods has substantial effects of the expected length of a vita at the end of six periods. These effects are magnified if we also include lower acceptance rates and longer paper lengths, which also seem to be part of the new publishing environment.

Next, we explore the existence of the Ellison Effect empirically using data from various sources to reconstruct the JEL-listed journal-publication record of almost every graduate of a U.S. or Canadian Ph.D.granting economics department from 1986 to 2000. Our central approach is to document research productivity (in this context measured by the quantity and quality of publications) among successive cohorts of new Ph.D.s using different controls to assure the robustness of the finding. This documentation leads to a number of findings about the heterogeneity of our sample that inform our efforts to investigate existence and strength of the Ellison Effect.

First, we find that approximately half of the graduates never publish at all, at least in those journals found in EconLit ${ }^{1}$. Of those graduates who do publish, however, the proportion of journal publications produced by each productivity-percentile of a cohort is remarkably stable: the publication "Lorenz curve" for each cohort is practically identical. Roughly speaking, among the publishing members of each cohort, 80 per cent of the output is produced by the top 20 per cent of the researchers while the top one percent of researchers produces approximately 14 percent of all publications.

\footnotetext{
${ }^{1}$ This percentage is also found for a small sample of graduates from 1997 by Stock and Siegfried (2006), for a sample of graduates from 1969-1988 by Hutchinson and Zivney (1995), and for a sample of European economists by Combes and Linnermer (2003).
} 
Second, the institution from which students receive their Ph.D'.s has a significant impact on the quality and quantity of their published research. Publishing graduates of top thirty departments produce more than three times as many AER equivalent pages and papers than do their counterparts from non-top thirty departments $^{2}$. Furthermore, for all cohorts, the average quality of each published paper and page is about three times better for graduates of the top programs compared to the non-top programs.

In light of this, we divide our data in three ways. First, we restrict attention to Ph.D.s who produce at least one published paper in a JEL indexed journal within six years after graduation on the grounds that this "publishing population" is the only part of the sample for which research is an objective. For this subsample, we make a distinction between graduates of "top thirty" and "non-top thirty" departments based on representative research rankings. One might think of this as an "ex ante" predictor of publication success $^{3}$. We also make a distinction based on the publication productivity percentile of researchers as calculated by the length of the vita at the sixth year after graduation to test if there are differences between scholars with different "ex post" publication success.

Our major finding is that there is evidence of an Ellison Effect. The strength of this evidence, however, depends on whether we use AER equivalent pages or AER equivalent publications as measure of research productivity. It also varies depending on whether we look at graduates of top thirty or non-top thirty institutions, and whether we look at the ex post more-productive or less-productive scholars.

In particular, the longer "time to build" process documented by Ellison (2002) has a measurable, but not uniformly dramatic, effect on publication success of all cohorts in terms of AER equivalent pages published by graduates of the top thirty programs. For these scholars, the productivity (that is, publishing success) of older cohorts is on average higher than the productivity of mid cohorts, and the productivity of the middle cohorts higher than that of the youngest cohorts. In contrast, there is no such pattern of declining productivity for the non-top thirty departments using AER equivalent pages as a measure. In both of these cases a distinct humped-shaped pattern of life cycle research productivity extends across and within cohorts: annual productivity rises until about the sixth year after graduation and then falls fairly quickly to about $60 \%$ of the peak.

When we look at the number of AER equivalent publications instead of pages published at the end of six years, we find large and statistically significant declines in productivity over time for graduates of both the top and non-top thirty departments. By this measure for graduates of the top thirty programs, the oldest cohort is $45 \%$ more productive than the middle cohorts and $65 \%$ more productive than the youngest. The middle cohorts in turn, are $13 \%$ more productive than the youngest cohorts. For non-top thirty departments, the oldest cohort is $19 \%$ more productive than the middle and $58 \%$ more productive than the youngest, while the middle cohorts are $33 \%$ more productive than the youngest cohorts.

For the ex post measure of publication success using productivity percentiles, the effects are even more pronounced: as we compare higher quintile ranges across cohorts, the dominance of older cohorts over younger cohorts, and the chronological ordering of cohorts in research productivity become more evident. This means that top performers of each cohort have been hit more severely by the publication bottleneck.

This, in conjunction with the finding that pages published are similar across cohorts (at least for the top thirty departments), is consistent with Ellison's (2002) documentation of the increasing length and decreasing number of published papers, and suggests two things. First, it exposes a significant methodological question

\footnotetext{
${ }^{2}$ We use the ranking from Coupe (2003) to determine the top thirty U.S. and Canadian economics departments. His ranking appears highly correlated with other popular rankings.

${ }^{3}$ Later in the paper we go into more detail about the rankings we used and the various robustness checks we carried out with respect to this.
} 
about the best way to measure productivity of departments, graduate programs, and individual scholars. Productivity patterns over time look different depending on whether papers or pages are chosen as a basis of comparison. We argue that what the profession values when granting tenure, giving raises, or making senior hires is the number of lines on a CV and the quality of the research papers on those lines. It is much harder to distill this into the number of AER-quality weighted pages, and we suspect that this is seldom attempted in practice. If this speculation is true, then it is important to look at AER equivalent papers rather than AER equivalent pages. Second, when AER equivalent papers are used as the productivity metric, there is a significant drop-off in the weighted quality of the CVs of Ph.D. graduates over time. Thus, unless we believe that recent graduates are fundamentally of poorer quality, the same quality of tenure candidate is significantly less productive today than 10 or 15 years ago. We will explore the robustness of this finding and its implications below.

While our primary focus in this paper to investigate the existence of the Ellison Effect, these data allow us to investigate the relative performance of graduate programs in terms of the research output of their Ph.D.s. This allows us to construct a new type of departmental ranking system that can be compared with other, more traditional systems which focus on the publications of faculty members at a particular department. We find that MIT, Princeton, Harvard and Rochester do best by this quality measure and more generally that the rankings of other departments does not entirely agree with more traditional measures that use faculty output.

In the remainder of the paper we first develop a simple model using specific, plausible parameter values and show how the change in "time to build" documented by Ellison (2002) affects the time-profile of an individual's vita. We then describe our data and document within and across cohort research productivity patterns and changes. Finally we investigate life cycle effects and cohort effects on Ph.D.s' research productivity and discuss what they imply for the existance of the Ellison Effect.

\section{An Illustrative Model}

Our purpose here is not to develop a general model of lifetime production and consumption, but rather to focus on a simple partial-equilibrium model that highlights the effects of a change in the time between submission and acceptance of a manuscript. The focus is on the period of time between entry into the academic workforce and the time of decision on tenure, namely six years. It is undoubtedly consistent with a more general model such as found in Levin and Stephan (1991), in which individuals optimize over their lifetimes by choosing their allocation of time between labor and leisure.

\subsection{Model Parameters and Solutions}

We construct a model in which there are five exogenous parameters:

- $s$ : the length of a manuscript ${ }^{4}$;

- $P_{0}$ : an individual's stock of unpublished papers at the time he receives a Ph.D. (thus $P_{0}$ is the number of manuscripts initially submitted to journals);

- $m$ : the individual's production of manuscript pages (per-year);

\footnotetext{
${ }^{4}$ Ellison (2002) documents that $s$ has increased over time at a greater rate than the number of high-quality journal pages published. While he speculates on the causes of this change, he does not offer conclusive evidence of a particular cause. Thus, we treat this as exogenous.
} 
- $\Delta$ : the "time to build" lag between when an individual's stock of unpublished manuscripts is submitted and when a decision on acceptance is received;

- $a_{t}$ : the percentage of the stock of an individual's unpublished manuscripts that were newly-submitted at $t-\Delta$, that are accepted for publication at time $t$.

Of course, in a more complete model, these exogenous variables would be endogenous and would reflect optimal choices of individual producers and the supply of journal pages available.

An individual's number of newly-submitted manuscripts at any time $t$ is denoted by $P_{t}$, and the number of newly-submitted pages is denoted by $p_{t}$. Thus, given that manuscripts have $s$ pages, $\left(p_{t} / s\right)=P_{t}$.

To summarize, we assume that an individual arrives in the profession with a stock $P_{0}=\left(p_{0} / s\right)$ of manuscripts. Each year after that, the individual writes $M=m / s$ manuscripts, where $m$ and $s$ are exogenous constants. Each year, all individuals submit every one of their existing unpublished manuscripts that are not in the evaluation process. Then, after a specified period of time, a percentage $a$ of these newly-submitted manuscripts are accepted.

To capture the change in the time between submission and publication emphasized by Ellison (2002), we consider two scenarios. In the first scenario, the exogenous percentage $a$ of newly-submitted manuscripts are accepted for publication the year following submission. Thus, the time to build is one period $(\Delta=1)$. In the second scenario, the exogenous percentage $a$ of newly-submitted manuscripts are accepted for publication two periods after submission. Thus, the time to build is two periods $(\Delta=2)$. To distinguish between these two cases, we denote parameters and variables associated with the one-period lag between submissions and acceptances by putting a "tilde" over the symbol. That is, in the first scenario the number of newly-submitted manuscripts at time $t$ is denoted as $\widetilde{P}_{t}$ and so forth.

With a one-period submission-acceptance lag, the number of newly-submitted manuscripts at time $t$ evolves according to the following first-order difference equation:

$$
\widetilde{P}_{t}=\tilde{M}+\widetilde{P}_{t-1}-a \widetilde{P}_{t-1}=\tilde{M}+(1-a) \widetilde{P}_{t-1}
$$

This says that the number of newly-submitted papers at time $t$ equals the previous period's submissions plus new additions $\tilde{M}$ minus accepted submissions from the previous period $a \widetilde{P}_{t-1}$. With the exogenously given original stock of unpublished papers $P_{0}$, the solution to this difference equation is found by well-known methods to be:

$$
\widetilde{P}_{t}=\sum_{i=0}^{t-1} \tilde{M}(1-\tilde{a})^{i}+(1-\tilde{a})^{t} \widetilde{P}_{0}=\left(\frac{\tilde{M}}{\tilde{a}}\right)+\left(\widetilde{P}_{0}-\left(\frac{\tilde{M}}{\tilde{a}}\right)\right)(1-\tilde{a})^{t}
$$

The number of acceptances per year, denoted by $\tilde{A}_{t}$, is the

$$
\tilde{A}_{t}=a \widetilde{P}_{t-1}
$$

The length of an individual's vita at any time t, denoted by $\tilde{V}_{t}$, is thus given as

$$
\tilde{V}_{t}=\tilde{V}_{t-1}+\tilde{A}_{t}
$$

Now consider our second scenario, in which the time between acceptance and publication is two periods. In this case, the number of newly-submitted manuscripts evolves according to the following second-order 
difference equation:

$$
P_{t}=M+P_{t-2}-a P_{t-2}=M+(1-a) P_{t-2}
$$

The key difference here from the first scenario is that newly-submitted manuscripts have to wait for two periods for a decision. As a result, submitted manuscripts at time $t$ will still be waiting for a decision at time $t+1$; hence those manuscripts will be contained neither among new journal submissions at time $t+1$, nor among accepted manuscripts at time $t+1$, denoted by $A_{t+1}$.

There are two initial conditions that apply to this problem: $P_{0}$ is given and $P_{1}=M$. Thus, the solution to (5) will be

$$
P_{t}=\frac{M}{a}+B_{1} \theta_{1}^{t}+B_{2} \theta_{2}^{t}
$$

where $B_{1}$ and $B_{2}$ satisfy the two boundary conditions

$$
\begin{aligned}
B_{1}+B_{2}+\frac{M}{a} & =P_{0}, \\
\frac{M}{a}+B_{1} \theta_{1}+B_{2} \theta_{2} & =M,
\end{aligned}
$$

and

$$
\theta_{i}= \pm \sqrt{1-a}, i \in\{1,2\}
$$

Alternatively, we can write the solution as

$$
P_{t}=\sum_{i=0}^{\frac{t}{2}-1} M(1-a)^{i}+(1-a)^{\frac{t}{2}} P_{0}=\left(\frac{M}{a}\right)+\left(P_{0}-\left(\frac{M}{a}\right)\right)(1-a)^{\frac{t}{2}}
$$

when $t$ is even, and

$$
P_{t}=\sum_{i=0}^{\frac{t-3}{2}} M(1-a)^{i}+(1-a)^{\frac{t-1}{2}} P_{1}=\left(\frac{M}{a}\right)\left(1-(1-a)^{\frac{t+1}{2}}\right)
$$

when $t$ is odd.

The number of acceptances per year, denoted in this scenario as $A_{t}$, are

$$
A_{t}=a P_{t-2}
$$

Thus, the length of an individual's vita in this scenario, denoted as $V_{t}$, is

$$
V_{t}=V_{t-1}+A_{t}
$$

\subsection{Calibrated examples}

To give some sense of the quantitative implications of the model, we calibrate the model based on plausible values of the parameters from the work of Ellison (2002). We explore three separate changes to the publishing environment that Ellison discusses: an increase in publication lags, a decrease in acceptance rates, and increase in the length of manuscripts. 
First, we consider a base case meant to represent the historical publishing environment. We take a benchmark of a $20 \%$ acceptance rate, one new paper per year as flow of production, an initial stock of three papers at graduation and a one year "Time to Build":

$$
\text { (1) } \tilde{a}=0.20, \tilde{M}=1 \text { and } \tilde{P}_{0}=3
$$

Second, we consider the effects of increased delays. We change the time to build to two years, but keep the same set of parameter values otherwise:

$$
\text { (2) } a=0.20, M=1 \text { and } P_{0}=3
$$

Third, we go back to a one period lag, but we consider the effect of increasing manuscript length by one third so that both initial stock and flow of new manuscripts decreases to $75 \%$ of the two cases above: ${ }^{5}$

$$
\text { (3) } \tilde{a}=0.20, \tilde{M}=0.75 \text { and } \tilde{P}_{0}=2.25
$$

Finally, we consider a one period lag and no increase in manuscript length, but decrease the acceptance rate to $12 \%:^{6}$

$$
\text { (4) } \tilde{a}=0.12, \tilde{M}=1 \text { and } \tilde{P}_{0}=3
$$

The results are shown in Table 1, and they reveal that new Ph.D.s trying to publish in the historical regime (case 1) are significantly more productive than new Ph.D.s facing any one of the three changes considered above. Agents publishing under the historical regime were $75 \%$ more productive than agents facing a two period time to build, $33 \%$ more productive than agents who must publish longer manuscripts, and $42 \%$ more productive than agents facing lower acceptance rates.

Table 1. The Effect of Lags, Acceptance Rate and Manuscript Length on CVs

\begin{tabular}{ccccc}
\hline \hline & \multicolumn{4}{c}{ Length of Vitae } \\
\cline { 2 - 5 } & $(1)$ & $(2)$ & $(3)$ & $(4)$ \\
Year & One year delay & Two year delay & $\begin{array}{c}\text { Monuscript } \\
\text { Mow Acceptance }\end{array}$ & Rate \\
\hline 1 & 0.60 & 0 & 0.45 & 0.36 \\
2 & 1.28 & 0.60 & 0.96 & 0.80 \\
3 & 2.03 & 0.80 & 1.52 & 1.30 \\
4 & 2.18 & 1.48 & 2.11 & 1.87 \\
5 & 3.65 & 1.84 & 2.74 & 2.50 \\
6 & 4.52 & 2.58 & 3.40 & 3.18 \\
\hline
\end{tabular}

These drops are substantial, and would be even more so if we subjected new Ph.D.s to all three changes at once as we do in the real world. Of course, new Ph.D.s may be aware of the current publication environment

\footnotetext{
${ }^{5}$ Ellison finds that articles increased in page length about 33\%, from about 18 pages to 24 .

${ }^{6}$ Note that the increase in manuscript length that Ellison documents implies that if the annual page budgets of journals has not increased (which is substantially the case at least with the top journals) then the acceptance rate, $a$, should fall. Add to this the number of submissions seems to be going up each year, and that for the few journals that actually report acceptance rates, the rates have gone down, and there is strong reason to believe that we see lower acceptance rates in general at economics journals in more recent periods.
} 
and may be responding. For example, they may submit more papers while a graduate student or stay in graduate school longer in order to have a better chance at tenure.

\section{Data}

The panel dataset we construct consists of two parts: a census of Ph.D. recipients from academic institutions in the US and Canada who received their economics Ph.D.s between 1986 and 2000 and a complete record of the journal publications of these individuals for the years 1985 to 2006 in EconLit listed journals.

\subsection{Economics Ph.D. Holders}

The record of economics Ph.D. recipients was constructed from two sources. The definitive source is the list provided by the American Economic Association (AEA), based upon an annual survey of economic departments. We use the Economics Ph.D. list of the AEA that records economics Ph.D. recipients beginning in 1985, and we supplement the data with information from the "2003-2004 Prentice Hall Guide to Economics Faculty by Hasselback". This directory contains information about current faculty members of all economics departments in the US, and of well-known Canadian and European research universities. Using the information about faculty members' graduation year and Ph.D. granting institution found in the Hasselback, a more comprehensive dataset of records of economics Ph.D. recipients from 1986 to 2000 was created. The number of Ph.D. recipients listed in both the AEA economics Ph.D. list, and in Hasselback is shown in Table A.1 in the appendix. The total number of Ph.D. recipients in a given year is not simply the sum of the entries from each source as there is considerable overlap between them. From 1988 to 2000 the number of Ph.D.s granted is fairly stable at about 1,000 per year. The significant growth from 1986 to 1988 may be due to less comprehensive coverage of Ph.D.s early in the AEA survey. Pooling all years, the panel contains 14,271 economics Ph.D.s.

\subsection{Journal Publications}

The record of journal publications is obtained from two different sources. Our main source is the EconLit Publication Database. The number of publications for the years 1985 to 2006 recorded in EconLit is listed in Table A.2 in the appendix. The number of papers has grown from about 9,500 in 1984 to almost 26,000 in 2005. Pooling all years, the panel of publications contains 368,672 peer-review papers. Of course, only a fraction of these are coauthored by Ph.D.s in our sample ${ }^{7}$.

The International Bibliography of Social Sciences (IBSS) database was used to obtain additional information on journal publications that have more than three authors. The reason for this is that EconLit reports only the first author's name, if a journal publication has more than three authors. There were 1,125 such occurrences in the EconLit journal publication database, and 558 of those were in top 25 journals.

\subsection{Supplemental data}

Raw counts of publications are imperfect measures of the research productivity of individual scholars because of the variation in the quality of those publications. The journal rankings and journal quality indexes from Kalaitzidakis, Mamuenas and Stengos (2003) are used to account for this variation. We convert their journal

\footnotetext{
${ }^{7}$ Fafchamps, van der Leij and Goyal (2006) and Goyal. van der Leij and Moraga-Gonzalez, (2006) construct a similar sample of published papers, but focus on the nature of the coauthor network rather than changes in publication rates across cohorts.
} 
quality indexes into American Economic Review (AER) equivalence, meaning that we express quality of each journal as a fraction of AER quality and use these weights in calculating numbers of AER equivalent publications and AER equivalent pages in our analysis. Ph.D.s in our database published in 992 different journals that are indexed in EconLit. The top 65 of these journals carry weights for AER equivalence as listed in Table A.3 in the appendix. We assign each of the remaining journals a weight of 0.012 . That is, according to the impact-adjusted ranking of peer-reviewed journals in economics, 12 pages in the AER (a relatively short paper) are equivalent to 1000 pages in the 66th ranked journal.

One might worry that our results might be highly dependent on the specific quality index employed here. As a robustness check we use a discrete ranking for journal quality provided by Combes and Linnemer (2010), where journals are not assigned a unique quality index but grouped into quality categories. Top 5 journals form the top quality group, denoted by AAA in Combes and Linnemer (2010), and we assign these journals a conversion rate of 1 to the AER. The next 15 journals form the second quality group (denoted by AA), and we assign these journals a conversion rate of $\frac{2}{3}$ to the AER. The next 82 journals form the third quality group (denoted by A), and we assign these journals a conversion rate of $\frac{1}{3}$ to the AER. ${ }^{8}$ Fortunately, the qualitative results obtained are similar regardless of which approach is used to ranking journals. ${ }^{9}$.

By matching manuscripts by authors in our Ph.D. panel with the indices of journal quality, we calculate the number of AER equivalent pages for article $i$ in journal $j$ as:

$$
\text { AER Pages }_{i j}=\frac{(\text { raw pages })_{i}(\text { journal index })_{j}}{(\text { authors })_{i}}
$$

where "raw pages" is the length of the manuscript, "journal index" is the quality weight converting the number of pages in journal $j$ into an equivalent number of pages of the AER, and "authors" is the number of authors of the manuscript. Dividing by number of authors we assign each author an equal share of credit for the research output. We also analyze how productivity measures change when we give each author full credit for the research output, and in this case we don't divide by the number of authors. Taking the sum of this index over all publications by an individual Ph.D. recipient in a specific year, gives the publication quality index for this individual in that year.

Similarly, the number of AER equivalent publications for article $i$ in journal $j$ is calculated as:

$$
\text { AER Publications }{ }_{i j}=\frac{(\text { journal index })_{j}}{(\text { authors })_{i}}
$$

The focus of our analysis is the impact of the ongoing slowdown in the publication process on the productivity of vintages of Ph.D.s indexed by their year of graduation. Since the variation in productivity across individuals at a point in time is immense, we also examine subsets of the panel for evidence of a slowdown. This entails controlling for life cycle patterns of productivity as well as conditioning on the ranking of the institution the Ph.D. received her degree.

\footnotetext{
${ }^{8}$ Combes and Linnemer (2010) group journals into six quality groups: AAA, AA, A, B, C, and D. We use the AER conversion rate of 0.12 for all journals in categories $\mathrm{B}, \mathrm{C}$, and $\mathrm{D}$.

${ }^{9}$ Whenever we refer to AER equivalent pages or AER equivalent publications in this paper, the AER equivalence is obtained by employing indices provided by Kalaitzidakis et al. (2003) unless otherwise noted.
} 


\section{Research Productivity of Cohorts by Flows and Stocks of Pub- lications}

The main goal of our empirical study is to evaluate the consequences of the slowdown in the publication process across cohorts of new Ph.D.s. As one might expect, there is considerable variation in the publication records of the approximately 1,000 individuals who receive Ph.D. in U.S. and Canada each year. For example, in most cohorts and in most departments, about 40 to 60 percent of graduates fail to publish a single paper in an EconLit listed journal in their first six years after graduation. These graduates are eliminated from the sample on the grounds that we wish to focus attention on graduates with scholarly research ambitions. Thus, when we use the term "graduates" in what follows it should be taken to mean "graduates who have published at least one paper in an EconLit listed journal within their first six year of graduation." Ph.D.s are organized into five cohorts, each pooling three consecutive years of Ph.D. graduates. For example, the 1987 cohort consists of individuals who had their Ph.D. conferred in either 1986, 1987 or $1988 .{ }^{10}$

\subsection{Productivity Distribution within Cohorts}

An interesting way to characterize within cohort heterogeneity is to use an "intellectual Lorenz curve" to quantify the inequity of contributions in each cohort to the aggregate flow of peer-review publications. Table 2 shows the cumulative distribution of all AER equivalent pages and publications in our panel of peer-review publications as a function of the productivity ranking of Ph.D.s at their sixth year after graduation.

Table 2. Intellectual Lorenz Curve

\begin{tabular}{|c|c|c|c|c|c|c|c|c|c|c|}
\hline & \multicolumn{5}{|c|}{ Percent AER Pages } & \multicolumn{5}{|c|}{ Percent AER Publications } \\
\hline & 1987 & 1990 & 1993 & 1996 & 1999 & 1987 & 1990 & 1993 & 1996 & 1999 \\
\hline Top $1 \%$ & 13.3 & 14.5 & 16.2 & 13.7 & 15.7 & 11.9 & 13.2 & 14.1 & 12.7 & 12.9 \\
\hline Top $5 \%$ & 42.7 & 45.7 & 44.2 & 43.1 & 45.5 & 37.5 & 39.4 & 39.6 & 39.2 & 40.1 \\
\hline Top $10 \%$ & 61.7 & 64.4 & 62.8 & 62.9 & 63.7 & 56.6 & 58.0 & 57.5 & 58.1 & 58.2 \\
\hline Top $20 \%$ & 81.6 & 82.5 & 81.7 & 82.1 & 82.7 & 78.1 & 78.4 & 78.1 & 78.7 & 79.0 \\
\hline
\end{tabular}

The top $1 \%$ of producers generates about 13 to $16 \%$ of all AER equivalent pages. The top $10 \%$ produces more than $60 \%$ of all published pages and the top $20 \%$ produces more than $80 \%$ of the output. These proportions are robust across all cohorts and does not change significantly when AER equivalent publications are used in place of AER equivalent pages, especially when top 1\% and top 5\% of Ph.D.s are considered. Thus the distribution of research productivity within each cohort is very skewed, however it is consistent across cohorts whether we consider AER equivalent pages or AER equivalent publications.

\subsection{Graduates from Top Thirty and Non-Top Thirty Institutions}

As documented in the prior section, approximately half of Ph.D.s never publish, and even restricting attention to those Ph.D.s who publish, we observe a very skewed productivity distribution. Thus, our data confirms the conventional wisdom that a very small but highly productive group of Ph.D.s create a disproportionately large share of total publications. Although there are always exceptions and outliers, the best performers

\footnotetext{
${ }^{10} \mathrm{Ph}$.D. cohorts defined in this way are also used in subsequent parts of the paper, except for the regression analysis.
} 
are mostly graduates of top research universities. We therefore separate all the Ph.D.s in our dataset into two groups: graduates of top thirty economics departments and graduates of non-top thirty economics departments. We use economics departments' ranking of Coupe $(2003)^{11}$ for our analysis.

Which departments are "top thirty" is open to question, of course, and could be calculated in several different ways. Given the length of time covered by this study (fourteen years) it is doubtless the case that departments have moved in and out of this group. It is not our purpose to make any definitive judgment on which departments deserve this recognition. In our view, it would be better to view our division of departments into two groups as an effort to study how a representative set of "top departments" performs against "non-top" departments.

Table A.4 in the appendix provides two rankings of the top thirty departments in U.S. and Canada. In the left column in Table A.4 department ranking of Coupe (2003) is reproduced, where departments are ranked by the productivity of their faculty members. Alternatively, one can argue that a department's true quality is measured by its graduates' productivity ${ }^{12}$. Following this idea, department ranking presented in the right column in Table A4 is based on our own calculations. We rank departments according to their Ph.D.s' productivity, which is measured as the average number of AER equivalent publications accumulated at the sixth year after graduation. Figure 1 shows the distribution of AER equivalent publications per graduate of each of the top thirty departments aggregated across all cohorts.

It is interesting to see that the Coupe ranking that focuses on faculty research quality does not line up particularly well with this measure which instead focuses on the research quality of graduates of these programs. Potential graduate students might do well to consider the implied ranking of departments given here when deciding where to apply for graduate training.

\subsection{Life Cycle Productivity Measured by Flows of Publications}

We begin by exploring the annual productivity of graduates of the top thirty departments and non-top thirty departments by various measures. The first measure of productivity is the annual number of raw pages published by graduates of the top thirty economics department and the remaining departments in our dataset. Young scholars at top and non-top thirty departments share a very similar career-cycle pattern of productivity. Annual productivity steadily rises from the year before the Ph.D is granted to a peak at about the fifth year. Productivity then drops off at a decreasing rate for the remaining years in our sample to about $60 \%$ of the peak value. This qualitative pattern also holds for all cohorts in both top and non-top thirty departments. It is certainly possible that productivity rises while new Ph.D.s are "eating their yolk". As they exhaust the stock of research questions they studied in graduate school, they become less productive. However, it is at least a little suspicious that this capital stock happens to start declining exactly at the point that tenure decisions are made. Also note that the gradual decline from the fifth year on is consistent with the presence of an overhang of completed and submitted work done before the tenure decision that only is accepted in subsequent years. Thus, we find evidence that is at least broadly consistent with the remarkable hypothesis that incentives seem to work in the economics profession.

Figures 2 and 3 show life cycle productivity of graduates of top thirty and non-top thirty departments, respectively, in terms of number of published pages. Graduates of the top thirty departments peak at about

\footnotetext{
${ }^{11}$ Coupe (2003) ranks economics departments worldwide by the productivity of their faculty. There are only two economics departments within Coupe's top thirty that are outside U.S. and Canada: the London School of Economics and the University of Oxford. Since our dataset consists of U.S. and Canadian economics departments' Ph.D.s, we drop the London School of Economics and the University of Oxford and include Coupe's numbers 31 and 32 (both in the U.S.) instead.

${ }^{12}$ See for example Collins et al. (2000).
} 
11 raw pages published in their fifth years, and then slowly decline to about 7 pages. Graduates of the non-top thirty departments, in contrast, peak at about 6-7 pages published per year and then decline to about 4 pages per year. There seems to be no obvious chronological ranking of the productivity graphs by cohorts based on annual number of published pages.

Although published pages seems to be the standard way of measuring productivity in similar studies ${ }^{13}$ our view is that it does not capture the true productivity incentives faced by new members of the profession. Our experience is that lines on a CV (as opposed to pages published) is more valued by the profession for tenure, promotion, raises, and so on. There are at least two reasons to use manuscripts as the unit of account. First, each paper contains a self-contained research idea and some require more pages to fully articulate than others even when their inherent scientific value is quite similar. Second, there are significant variances in the length of research manuscripts across sub-fields of economics having to do with the content of the topic and the norms of exposition. This renders the page metric a somewhat dubious unit of account. We therefore consider the annual number of raw publications (that is, papers) published by members of our sample.

When we measure productivity in terms of number of published papers, we see a similar pattern as above for all cohorts with productivity peaking at about year five and then declining. Graduates of the top thirty departments peak at about 0.5 to 0.7 papers per year (see Figure 4), while non-top thirty peak at about 0.3 to 0.5 papers per year. Chronological ranking of the productivity across cohorts that was not apparent in published pages becomes now apparent revealing a ranking of cohorts with the oldest cohorts publishing the most and the youngest the least.

These first two measures are still limited in that they take no account of where graduates publish their papers. We therefore produce comparable figures but weight publications according to journal quality to get AER equivalent pages and papers published annually. As mentioned above, our journal quality index is based on Kalaitzidakis et al (2003). Considering AER equivalent pages, we continue to see the familiar productivity peak at about five years. Graduates of the top thirty departments peak at about 1.5 to 2 AER pages per year, and this is shown in Figure 5, while non-top thirty peak at about 0.4 to 0.5 pages. Thus, we see that top thirty graduates are more than 3 times as productive as non-top thirty graduates compared at their peak annual productivity levels.

Figure 6 shows an alternative version of Figure 5, where number of AER equivalent pages is based on the discrete quality index provided by Combes and Linnemer (2010). Graduates of the top thirty departments peak at about 4 to 4.5 AER pages per year, while non-top thirty graduates peak at about 1.4 to 1.7 pages. Comparing peak levels of their annual productivities, we see that top thirty graduates are about 3 times more productive than non-top thirty graduates.

Moving to AER equivalent publications (again using Kalaitzidakis et al (2003) as this is our default quality index), graduates of the top thirty departments peak at about 0.08 to 0.13 AER publications per year compared to 0.02 to 0.03 for non-top thirty departments. Again we see that top thirty graduates are more than three times as productive as non-top thirty graduates compared at their peak annual productivity levels.

\subsection{Life Cycle Productivity and Coauthorship}

It is typical to divide the credit evenly over the authors of a paper, as we have done in the data reported above. Thus, if there are two authors on a ten page AER paper, they are each credited with producing five AER pages. It is debatable whether or not this is fair. It surely takes more than half the time to write

\footnotetext{
${ }^{13}$ See for example Combes and Linnemer (2003) and Rauber (2008).
} 
a coauthored paper than an equivalent single authored paper (as all the authors of the current paper will surely attest). Again, our experience suggests that the profession tends to look at lines on a CV and only make some smaller discount for coauthorship. Thus, one might wonder what would happen if we gave all authors full credit for a paper.

We find the same pattern of productivity peaking at five years and the same slight tendency of the older cohorts to be more productive than the younger cohorts when we do not discount for coauthorship. However, it seems that the drop off after five years is not as steep. This might reflect increased coauthorship with graduate students or more opportunities for collaboration as a scholar becomes better known. The overall effect is to raise the peak productivity in terms of AER equivalent pages to a range from 2.4 to 3.2 for top thirty graduates and to a range from .6 to .8 for non-top thirty graduates. This compares to 1.5 to 2 AER pages per year for top thirty graduates, and .4 to .5 for non-top thirty graduates with coauthor discounts.

A related question is whether there have been secular changes in the pattern of coauthorship over the years. Based on our extensive panel, coauthorship does appear to be on the rise. This may be due to the increasing importance of the Internet and email which lowers the transactions cost of working with authors outside one's department. We find that the average number of authors per publication in all EconLit journals rises from 1.35 authors in 1984 to 1.6 authors 2001, while for the top twenty journals, it goes from about 1.5 to 1.8 (see Figure 7).

This secular trend of increased coauthorship is in line with the observation that younger cohorts have on average more coauthors in their publications. We see a very interesting life-cycle pattern in coauthorship as well. Figure 8 shows the average number of authors of publications that are affiliated with at least one member of the respective cohort.

We observe a U-shaped life cycle for coauthorship across cohorts. This is a similar observation to that presented by Rauber and Ursprung (2008) about German academic economists. Coauthorship tends to be much less frequent between 1st and 4th years after graduation. This pattern remains consistent over all cohorts. As we move from older to younger cohorts, we observe that the U-shape is preserved and gradually shifted upwards. This indicates that although the coauthorship pattern for younger cohorts is similar to that for older cohorts, younger cohorts collaborate with larger numbers of coauthors compared to older cohorts over their life cycle. This might be a rational response to increased publication lags, because increased coauthorship would allow Ph.D.s to produce more manuscripts. More manuscripts may or may not lead to more publications (especially after controlling for quality), and we will investigate this in the next section.

\subsection{Life Cycle Productivity Measured by Stocks of Publications}

We now turn to cumulative productivity measures to investigate how different cohorts compare to each other at the same point in time, namely at the end of the sixth year after graduation. We decide to focus on the sixth year for cumulative productivity analysis since tenure or promotion decisions are mostly based on the evaluation of cumulative productivity around this time.

We rank Ph.D.s in each cohort based on their cumulative productivity at their sixth year after graduation. For each cohort, total number of AER equivalent pages and papers produced by Ph.D.s at 99th, 95th, 90th, 85th, 80th, 75th and 50th (median) percentiles are reported in Table 3. 
Table 3. Performance of Various Percentiles

\begin{tabular}{ccccccccccc}
\hline \hline & \multicolumn{4}{c}{ AER Equivalent Pages } & \multicolumn{4}{c}{ AER Equivalent Publications } \\
\cline { 2 - 11 } Percentiles & 1987 & 1990 & 1993 & 1996 & 1999 & 1987 & 1990 & 1993 & 1996 & 1999 \\
\hline 99th & 70.0 & 57.2 & 69.6 & 57.3 & 65.1 & 3.87 & 3.06 & 3.23 & 2.45 & 2.48 \\
95th & 33.9 & 28.0 & 27.1 & 26.7 & 24.3 & 2.00 & 1.48 & 1.33 & 1.28 & 1.22 \\
90th & 20.5 & 14.5 & 15.9 & 15.0 & 15.0 & 1.34 & 0.98 & 0.85 & 0.76 & 0.73 \\
85th & 13.6 & 9.4 & 10.6 & 9.4 & 9.7 & 0.99 & 0.62 & 0.61 & 0.52 & 0.51 \\
80th & 8.4 & 6.2 & 7.3 & 6.2 & 6.3 & 0.62 & 0.43 & 0.44 & 0.37 & 0.37 \\
75th & 6.2 & 4.0 & 5.3 & 4.0 & 4.3 & 0.45 & 0.31 & 0.30 & 0.26 & 0.26 \\
Median & 1.1 & 0.9 & 1.0 & 0.9 & 0.9 & 0.08 & 0.06 & 0.06 & 0.06 & 0.05 \\
\hline
\end{tabular}

Comparing different percentiles of productivity distribution within any cohort reveals that productivity is very skewed. Based on AER equivalent pages, a Ph.D. ranked at 99th percentile is more than twice as productive as a Ph.D. ranked at 95th percentile and a remarkable 60 to 70 times more productive than the median Ph.D.. One obtains similar results if one looks at AER equivalent publications instead of pages.

Comparing, on the other hand, a given percentile across cohorts, AER equivalent pages don't show a clear pattern, whereas AER equivalent publications do. Especially when we aggregate cohorts 1990 and 1993 into one large cohort, and cohorts 1996 and 1999 into another, the downward trend as measured in AER equivalent publications becomes evident at all percentiles reported here. These findings may have crucial implications for the tenure evaluation process of younger cohorts. Two Ph.D.s in different cohorts may be ranked at exactly the same percentile within their respective cohorts and yet the younger cohort member has fewer AER equivalent publications than the member of older cohort.

Table 4 provides an overview of various productivity measures attained by an average member of each respective cohort at the end of their sixth year after graduation. We provide two measures for the number of total publications: one which splits credit for a publication equally between coauthors, and one which gives full credit to each of the coauthors. Similarly we provide two versions of AER equivalent publications and AER equivalent pages: The first one is calculated as explained above, splitting credit equally between coauthors and using a continuous journal quality index. The second one is calculated by giving full credit to each of the coauthors. 
Table 4. Per capita output at the end of the sixth year after Ph.D.

\begin{tabular}{|c|c|c|c|c|c|}
\hline \multirow[b]{2}{*}{ Equal Credit to each coauthor } & \multicolumn{5}{|c|}{ Ph.D.s from Top Thirty } \\
\hline & 1987 & 1990 & 1993 & 1996 & 1999 \\
\hline Total Pages & 58.0 & 52.8 & 56.7 & 54.2 & 51.7 \\
\hline Total Publications & 3.58 & 3.04 & 2.99 & 2.76 & 2.47 \\
\hline Pages per publication & 16.2 & 17.4 & 19.0 & 19.6 & 20.9 \\
\hline AER Pages & 9.95 & 7.56 & 8.14 & 7.32 & 8.04 \\
\hline AER Publications & 0.61 & 0.43 & 0.41 & 0.36 & 0.37 \\
\hline \multicolumn{6}{|l|}{ Full credit to each coauthor } \\
\hline Total Pages & 82.0 & 76.5 & 82.9 & 81.5 & 82.3 \\
\hline Total Publications & 4.94 & 4.33 & 4.27 & 4.07 & 3.84 \\
\hline Pages per publication & 16.6 & 17.7 & 19.4 & 20.0 & 21.4 \\
\hline AER Pages & 14.9 & 10.9 & 12.2 & 11.4 & 13.6 \\
\hline AER Publications & 0.89 & 0.62 & 0.6 & 0.56 & 0.61 \\
\hline \multicolumn{6}{|l|}{ Ratio of 'Full' to 'Equal' Credit } \\
\hline AER Pages & 1.50 & 1.44 & 1.50 & 1.56 & 1.69 \\
\hline \multirow[t]{2}{*}{ AER Publications } & 1.46 & 1.44 & 1.46 & 1.56 & 1.65 \\
\hline & \multicolumn{5}{|c|}{ Ph.D.s from Non-Top Thirty } \\
\hline Equal Credit to each coauthor & 1987 & 1990 & 1993 & 1996 & 1999 \\
\hline Total Pages & 33.8 & 34.2 & 36.3 & 33.2 & 38.8 \\
\hline Total Publications & 2.57 & 2.38 & 2.36 & 2.0 & 2.16 \\
\hline Pages per publication & 13.2 & 14.4 & 15.4 & 16.6 & 18.0 \\
\hline AER Pages & 2.42 & 2.29 & 2.33 & 1.88 & 2.07 \\
\hline AER Publications & 0.19 & 0.17 & 0.14 & 0.11 & 0.12 \\
\hline \multicolumn{6}{|l|}{ Full credit to each coauthor } \\
\hline Total Pages & 51.0 & 51.2 & 55.3 & 51.4 & 63.6 \\
\hline Total Publications & 3.83 & 3.57 & 3.54 & 3.09 & 3.49 \\
\hline Pages per publication & 13.3 & 14.3 & 15.6 & 16.6 & 18.2 \\
\hline AER Pages & 4.04 & 3.7 & 3.9 & 3.04 & 3.55 \\
\hline AER Publications & 0.3 & 0.26 & 0.23 & 0.18 & 0.2 \\
\hline \multicolumn{6}{|l|}{ Ratio of 'Full' to 'Equal' Credit } \\
\hline AER Pages & 1.67 & 1.62 & 1.67 & 1.62 & 1.71 \\
\hline AER Publications & 1.58 & 1.53 & 1.64 & 1.64 & 1.67 \\
\hline
\end{tabular}

At the end of six years, cumulative productivity of graduates of the top thirty departments is consistent with the hypothesis that productivity is decreasing for younger cohorts. Based on total number of raw publications (see second row in Table 4 as well as Figure 9), the 1987 cohort is $45 \%$ more productive than the 1999 cohort. This ratio drops to $29 \%$ when we assign full credit for coauthored publications, however this is still quite substantial, and would certainly affect a tenure committee's view of a tenure candidate. To be more precise, at the end of six years, we test for each cohort pair the null hypothesis that cohort means are equal against the alternative hypothesis that older cohort outperforms the younger one. Comparing 1987 cohort to 1990 cohort, 1990 cohort to 1993 cohort, 1993 cohort to 1996 cohort, and 1996 cohort to 1999 
cohort, we obtain p-values of $0.0004,0.35,0.035$, and 0.0039 , respectively. For non-top thirty graduates, the story is less clear, because cohorts' productivity ranking does not follow a strictly decreasing trend, and cohorts do not line up as hypothesized from the old to the young, when compared at six years after graduation.

We get more definitive results for productivity when we look at AER equivalent publications for graduates of top thirty as well as non-top thirty departments. One can see that the 1990 and 1993 cohorts and the 1996 and 1999 cohorts, respectively have very similar productivity patterns (see Figure 10). Thus, we will aggregate these for both the top and non-top thirty departments. At the end of six years, the top thirty 1987, 1990+1993, and 1996+1999 cohorts published 0.61, 0.42, 0.37 AER equivalent publications over all, respectively. We see a very striking decline in productivity over time: the middle cohorts are $13 \%$ more productive than the youngest cohorts while the oldest cohort is $45 \%$ more productive than the middle and $65 \%$ more productive than the youngest. We test the null hypothesis that cohort means are equal against the alternative hypothesis that the older cohort outperforms the younger one. We obtain the following p-values: 0 for 1987 and $1990+1993,0$ for 1987 and 1996+1999, 0.0089 for $1990+1993$ and 1996+1999.

For non-top thirty schools we find at the end of six years, the 1987, 1990+1993, and 1996+1999 cohorts published $0.19,0.16,0.12$ AER equivalent publications, respectively. We see an overall trend in which the middle cohorts are $33 \%$ more productive than youngest cohorts while the oldest cohort is $19 \%$ more productive than the middle and $58 \%$ more productive than the youngest. We test the null hypothesis that cohort means are equal against the alternative hypothesis that older cohorts outperforms the younger one. We obtain the following p-values: 0.079 for 1987 and 1990+1993, 0.0003 for 1987 and 1996+1999, 0.0003 for $1990+1993$ and $1996+1999$.

The strong trend of individual cohorts lining up chronologically in decreasing productivity (with 1999 cohort being only slightly more productive than the 1996 cohort) does not hold, however, if we switch our productivity measure from AER equivalent publications to AER equivalent pages. As shown in Table 4, 1987 cohort is the most productive cohort, however other cohorts do not line up chronologically: 1993 cohort achieves higher productivity than 1990 cohort, and 1999 cohort outperforms 1996 cohort. Considering Ph.D.s from top thirty departments, although 1990 and 1993 cohorts together have higher average productivity than 1996 and 1999 cohorts together, this is not the case anymore when we assign full credit to each coauthor. Moreover, comparing different cohorts of top thirty departments using different policies to discount for coauthortship (namely equal credit and full credit), we see that the ratio of coauthor-not-discounted to coauthor-discounted AER equivalence measures, which is denoted as the "ratio of full to equal credit" in Table 4, decreases from 1987 cohort to 1990 cohort, but then increases from older to younger cohorts. Thus we find quality discounted rates of coauthorship increasing as cohorts get younger. This is in line with our discussion of coauthorship patterns over the life cycle of cohorts in the previous subsection.

This suggests a very important methodological and policy question about what is the right measure of productivity: AER equivalent publications or AER equivalent pages? Moreover, should coauthors share the credit or should they be assigned full credit? Our position is that tenure committees look at lines on a CV, first and page counts second, if at all. If this is true, then younger scholars look significantly less productive than their older colleagues. In part, this is because papers seem to have gotten longer on average over the years. This leads to a potential double whammy for assistant professors seeking tenure. First, by counting publications instead of pages, more recent tenure candidates will appear unfairly less productive than their colleagues who got tenure in the past. Second, a department that set a standard that could be met by say the top twenty percent of new tenure candidates who graduated in 1987 will find that it can be met perhaps 
by only eleven percent of those who graduated in 1999. This may be good or bad, but at least tenure committees should be aware of the implications of not adjusting tenure standards that reflect the current publishing environment of longer papers, lower acceptance rates and longer delays.

Another usefulg way to think about how publishing patterns have changed is to look at the ratio of AER equivalent publications to total publications. This is a measure of average publication quality across cohorts. One can think of this as a "signal to noise ratio" as it indicates what fraction of an AER-quality publication is contained in a given publication. As publication quality of a cohort decreases, the ratio of AER equivalent publications to total publications will decrease. Table 5 shows total number of publications within six years after obtaining Ph.D., number of AER equivalent publications, and the percentage of AER equivalent publications in total publications (hence the signal to noise ratio) across cohorts. We calculate AER equivalent publications using indices provided by Kalaitzidakis et al. (2003) as well as by Combes and Linnemer (2010). AER equivalent publications obtained by two different indices are very highly correlated, thus yielding very similar trends.

Table 5. Aggregate cohort output

\begin{tabular}{|c|c|c|c|c|c|c|c|c|c|c|}
\hline & \multicolumn{5}{|c|}{ Total publication output } & \multicolumn{5}{|c|}{ 'Signal to noise' ratio } \\
\hline & 1987 & 1990 & 1993 & 1996 & 1999 & 1987 & 1990 & 1993 & 1996 & 1999 \\
\hline \multicolumn{11}{|l|}{ Top 30 Ph.D.s } \\
\hline Total Publications & 1988 & 2531 & 2792 & 2468 & 2075 & & & & & \\
\hline AER (Combes) & 772 & 877 & 964 & 843 & 756 & 0.388 & 0.347 & 0.345 & 0.342 & 0.364 \\
\hline AER (Kalaitzidakis) & 340 & 359 & 387 & 325 & 313 & 0.171 & 0.142 & 0.139 & 0.132 & 0.151 \\
\hline \multicolumn{11}{|l|}{ Non Top 30 Ph.D.s } \\
\hline Total Publications & 1004 & 1494 & 1527 & 1228 & 1549 & & & & & \\
\hline AER (Combes) & 250 & 377 & 358 & 271 & 352 & 0.249 & 0.252 & 0.234 & 0.221 & 0.227 \\
\hline AER (Kalaitzidakis) & 72 & 105 & 93 & 68 & 86 & 0.072 & 0.070 & 0.061 & 0.055 & 0.056 \\
\hline \multicolumn{6}{|c|}{ Top 30 Ph.D.s relative to Non Top 30 Ph.D.s } & & & & & \\
\hline Total Publications & 1.98 & 1.69 & 1.83 & 2.01 & 1.34 & & & & & \\
\hline AER (Combes) & 3.09 & 2.33 & 2.69 & 3.11 & 2.15 & & & & & \\
\hline AER (Kalaitzidakis) & 4.72 & 3.42 & 4.16 & 4.78 & 3.64 & & & & & \\
\hline
\end{tabular}

Notes: The rows labelled Combes and Kalaitzidakis use AER equivalent weights from the

Combes and Linnemer (2010) and the Kalaitzidakis et al. (2003) studies to aggregate

publications in each cohort.

While it seems clear that the 1987 cohort of top thirty departments' graduates had higher quality publications on average by any measure, the signal to noise ratio decreases from the 1987 cohort to the 1996 cohort. However 1999 cohort performs better on quality than the previous three cohorts. Overall there is a clear trend of declining overall average publication quality of top thirty graduates except for the youngest cohort. Turning to cohorts of non-top thirty departments' graduates we find it difficult comparing 1987 
cohort to 1990 cohort: whether 1987 cohort outperforms 1990 cohort or not depends on the specific quality index, which can be interpreted as suggesting that the two cohorts don't differ much at all in quality. Younger cohorts perform worse than the oldest two cohorts, and 1999 cohort performs slightly better than 1996 cohort. Thus, we can say that signal to noise ratio has worsened across cohorts graduating from mid 80 s until late 90s. This partially confirms the conventional wisdom that the enormous growth of new journals and publication outlets has led to a decline in overall average publication quality ${ }^{14}$.

\section{$5 \quad$ Life Cycle and Cohort Effects}

Our analysis in preceding sections has shown that the hypothesized gradual downward shift in productivity across cohorts is not entirely obvious when only annual productivity is considered. We detect, however, that older cohorts do outperform younger cohorts if we look at cumulative instead of annual productivity. Comparing AER equivalent publications accumulated at the end of six years after graduation, we observe a gradual downward shift across cohorts. In this section we focus again on annual productivity of Ph.D.s. Our aim is to formally flesh out productivity differences across cohorts which manifest themselves clearly at a cumulative level but which are not as obvious at the annual level when only descriptive tools are used. The goal is to distinguish life cycle and cohort effects in the annual productivity measures. As Figures 2 to 6 reveal, an average Ph.D.'s annual publication productivity follows a distinct hump-shaped life cycle. The number of AER equivalent publications achieved at any given time is affected both by the location on life cycle after graduation and by cohort specific effects.

\subsection{Estimation Results and the Ellison Effect}

We estimate a pooled Tobit model of annual research productivity where we treat the dependent variable as a latent variable. Our dependent variable is the annual research output measured as the number of AER equivalent publications for a given individual at a given time (which is zero for nearly sixty percent of all observations in the raw data). Explanatory variables include time polynomials, dummy variables for the graduation year and a dummy variable to indicate whether the graduate is from a top 30 department. The dummy variables for the graduation year are the key variables of interest since they allow us to test the null hypothesis that younger cohorts are less productive than older ones.

Annual research productivity of individual $i$ at time $t$ is the dependent variable, with time measured as "years after graduation". A third degree polynomial in time captures the life cycle pattern of research productivity. All individuals' publication records from the first until sixth year after graduation are covered because our aim is to compare cohorts within their "tenure-track" period which corresponds to approximately the first six years after graduation. This leaves us with a total of 42,924 observations ${ }^{15}$.

Cohort effects are captured by dummy variables for graduation years that span from 1986 to 1999, and individuals with the same year of graduation are described as belonging to the cohort for that year. Observations extend to graduates in the year 2000 but the last dummy is dropped to avoid collinearity

\footnotetext{
${ }^{14}$ One should note that graduating cohorts have had approximately the same size from 1989 to 2000 . The suggested increase of publications by younger cohorts in lower quality outlets might have been a consequence of three things: being subject to increased publications lags, facing increased supply of economics Ph.D.s from non-U.S. and non-Canadian institutions (hence increased competition from the rest of the world), or a mix of the two.

${ }^{15}$ Publication records for most cohorts extend beyond six years. If we use all available years for each cohort in our pooled Tobit model, we would be using 81,051 observations. Estimating our model using these observations and correcting for the loss in time dummies' efficiency due to unbalanced panel, we obtain qualitatively the same results as with only six years as far as significance of time dummies and their signs are concerned.
} 
between the cohort dummies. Thus, the marginal effect of a given cohort dummy variable shows how the respective cohort performs relative to the graduates of 2000 cohort. The cohort dummies are not interacted with time polynomials: we are assuming the year of graduation affects the level of the life cycle and not its slope at different points in the life-cycle. If a slowdown in the publication process is occurring over time, the coefficients on the cohort dummies should decrease in value as we move in time from 1986 to 1999. Our hypothesis is that the coefficients on the graduation year dummy, i.e. cohort effect, will be highest in the initial year and decline over time as publication lags continue their upward trend. The specification also includes, Top30, a dummy variable that takes on the value 1 if individual $i$ is a graduate of a top thirty $\mathrm{PhD}$ program. This just shifts the conditional mean of the flow of publications but does not alter the shape of the life-cycle profile or the within-group year effects.

Marginal effects for coefficients from four different Tobit models are reported in Table 6 . The four Tobit models differ by their dependend variables. Column (1) reports marginal effects from regressing annual number of AER-equivalent publications adjusted for coauthorship (where credit from publication is equally shared among all coauthors) on life cycle effects, cohort effects, and a dummy variable capturing the ranking of the graudate institution. We use the significance of point estimates for cohort effects to determine whether a cohort outperforms another cohort in terms of research productivity.

Since one might claim that the coauthor-adjusted number of AER-equivalent publications is the conventional measure for research productivity that is used in most cases, and since we have been focusing on this particular productivity measure in the previous sections of the paper, we put this measure under the spot in this section. However we run the same Tobit model for three other productivity measures: we use the annual number of AER-equivalent publications without adjustment for coauthorship where each coauthor gets full credit for the publication (column (2)), the annual number of AER-equivalent publications where AER-equivalence is based on a discrete ranking ${ }^{16}$ of journals (column (3)), and the total number of annual publications without any quality weights (column (4)).

\footnotetext{
${ }^{16}$ Discrete ranking of journals is obtained from Combes and Linnemer (2010), as in the previous section.
} 
Table 6. Pooled Tobit Model- Marginal Effects

\begin{tabular}{|c|c|c|c|c|}
\hline & (1) & $(2)$ & $(3)$ & $(4)$ \\
\hline Top30 & $0.0208^{* * *}$ & $0.0306^{* * *}$ & $0.0375^{* * *}$ & $0.058^{* * *}$ \\
\hline \multicolumn{5}{|l|}{ Life cycle effects } \\
\hline$t$ & $0.0359^{* * *}$ & $0.0484^{* * *}$ & $0.0771^{* * *}$ & $0.2152^{* * *}$ \\
\hline$t^{2}$ & $-0.0054^{* * *}$ & $-0.0066^{* * *}$ & $-0.0116^{* * *}$ & $-0.0319 * * *$ \\
\hline$t^{3}$ & 0.00022 & 0.00023 & $0.0005^{*}$ & $0.0014^{*}$ \\
\hline \multicolumn{5}{|l|}{ Cohort effects } \\
\hline 1986 & $0.0218^{* * *}$ & $0.031^{* * *}$ & $0.0454^{* * *}$ & $0.1168^{* * *}$ \\
\hline 1987 & $0.0158^{* * *}$ & $0.0185^{* * *}$ & $0.0361^{* * *}$ & $0.093^{* * *}$ \\
\hline 1988 & $0.0121^{* * *}$ & $0.0125^{* * *}$ & $0.0282^{* * *}$ & $0.0846^{* * *}$ \\
\hline 1989 & 0.004 & 0.0007 & $0.011^{* *}$ & $0.041^{* * *}$ \\
\hline 1990 & $0.0059^{* *}$ & 0.0049 & $0.0189^{* * *}$ & $0.0645^{* * *}$ \\
\hline 1991 & $0.0088^{* * *}$ & $0.0092^{* *}$ & $0.0208^{* * *}$ & $0.0672^{* * *}$ \\
\hline 1992 & $0.0061^{* *}$ & 0.0056 & $0.0164^{* * *}$ & $0.06^{* * *}$ \\
\hline 1993 & 0.003 & -0.0001 & $0.0105^{* *}$ & $0.044^{* * *}$ \\
\hline 1994 & $0.0041^{*}$ & 0.0031 & $0.0139^{* * *}$ & $0.0509^{* * *}$ \\
\hline 1995 & 0.00032 & -0.002 & 0.0042 & $0.0242^{*}$ \\
\hline 1996 & 0.0005 & -0.001 & 0.0064 & $0.0325^{* *}$ \\
\hline 1997 & -0.0023 & -0.0064 & -0.0003 & 0.0093 \\
\hline 1998 & -0.0008 & -0.0021 & 0.0013 & 0.0136 \\
\hline 1999 & 0.0015 & 0.0009 & $0.0084^{*}$ & $0.0336^{* * *}$ \\
\hline$E(y)$ & 0.0472 & 0.0719 & 0.1276 & 0.406 \\
\hline$E(y \mid x, y>0)$ & 0.1865 & 0.2759 & 0.3542 & 0.9737 \\
\hline Observations & 42924 & 42924 & 42924 & 42924 \\
\hline
\end{tabular}

* significant at $10 \%$;* significant at $5 \%$;** significant at $1 \%$

Evidently, cohort effects decrease from older to younger cohorts, which means that the predicted difference in annual number of publications is higher between 2000 cohort and any cohort from late 1980s than between 2000 cohort and any cohort from late 1990s. This observation is robust across all four different measures of research productivity that we use in Table 6 . In order to better visualize the pattern that is revealed by cohort effects of graduates over fourteen years, Figure 11 plots the cohort effects from columns (1), (2), and (3) in Table 6. All three of them show very similar trends. Differences in productivity between 2000 cohort and other cohorts are more pronounced when we assign full credit to each coauthor instead of discounting for coauthorship. It is evident that there is a downward shift that begins with sharp declines in the late 1980s but which seems to settle into a steady-state pattern in the late 1990s. In the last few years, the annual 
flow differences across cohorts are too small numerically to be statistically distinguishable. Thus, most of the evidence of the slowdown comes in the first half of the cohort sample. The year 1986 seems somewhat of an outlier, so we discount that evidence, but subsequent nearby years are higher than later years, by a statistically significant amount.

Marginal effects of the Tobit model are evaluated around the conditional mean of the dependent variable and show how the conditional mean is affected by the life cycle effects, cohort effects, or the institution dummy. In order to give a better understanding for the magnitude of the marginal effects, we provide conditional and unconditional means of the respective productivity measure at the bottom of Table 6. Due to the nonlinearity of the Tobit model and our extensive use of dummy variables in this estimation, only limited intuition can be gained from studying the numerical values of marginal effects. Instead of analyzing quantitative aspects of these marginal effects, we focus on the sign and significance of them. The dummy variable for graduates of top thirty departments is found to be highly significant which confirms our earlier discussions and descriptive findings about the performance differences between graduates of top thirty and non-top thirty departments.

Results in Table 6 show that different ways of measuring research productivity yield different results in terms of statistical significance: 2000 cohort's research productivity cannot be statistically significantly distinguished from that of any cohort after 1991 when we use "the annual number of AER-equivalent publications with full credit to each coauthor" (column (2)) as a measure for the research productivity. On the other hand, when we use "the annual number of total publications" (column (4)) instead, then the picture changes: in this case, 2000 cohort is significantly outperformed by almost all other cohorts, except for the 1997 and 1998 cohorts.

In order to compare cohorts' research productivity pairwise, we make use of significance levels of cohort effects. This can be done by comparing the point estimate of the marginal effect of a graduation year dummy to the $95 \%$ confidence interval of another graduation year dummy's marginal effect. If the point estimate lies to the right of the $95 \%$ confidence interval of the other cohort's marginal effect, then we say that the latter cohort is outperformed by the former one. A more rigorous method, which we employ in our analysis below, is to run separate Tobit models, each of which take one of the fifteen cohorts as base. Then the signs and significance levels of cohort effects will reveal whether the base cohort is outperformed by other cohorts or outperforms other cohorts and at what significance level exactly. For this analysis we measure research productivity in terms of the annual number of AER-equivalent publications first, then we discuss other alternatives.

Results of the pairwise comparisons of cohorts' research productivity are summarized in Table 7. A '+' sign indicates that members of cohorts belonging to the year indicated in the row statistically significantly outperform members of the cohorts indicated in the columns in terms of research productivity. 
Table 7. Comparison across Cohorts: AER-Equivalent Publications with Equal Credit

\begin{tabular}{|c|c|c|c|c|c|c|c|c|c|c|c|c|c|c|}
\hline & 1987 & 1988 & 1989 & 1990 & 1991 & 1992 & 1993 & 1994 & 1995 & 1996 & 1997 & 1998 & 1999 & 2000 \\
\hline 1986 & & + & + & + & + & + & + & + & + & + & + & + & + & + \\
\hline 1987 & & & + & + & + & + & + & + & + & + & + & + & + & + \\
\hline 1988 & & & + & + & & + & + & + & + & + & + & + & + & + \\
\hline 1989 & & & & & & & & & & & + & $(+)$ & & \\
\hline 1990 & & & & & & & & & + & + & + & + & $(+)$ & + \\
\hline 1991 & & & $(+)$ & & & & + & $(+)$ & + & + & + & + & + & + \\
\hline 1992 & & & & & & & & & + & + & + & + & $(+)$ & + \\
\hline 1993 & & & & & & & & & & & + & $(+)$ & & \\
\hline 1994 & & & & & & & & & & & + & + & & $(+)$ \\
\hline 1995 & & & & & & & & & & & & & & \\
\hline 1996 & & & & & & & & & & & & & & \\
\hline 1997 & & & & & & & & & & & & & & \\
\hline 1998 & & & & & & & & & & & & & & \\
\hline 1999 & & & & & & & & & & & $(+)$ & & & \\
\hline
\end{tabular}

Note: "+" indicates the row cohort out-performed the column cohort at the $5 \%$ level of significance, and "(+)" indicates the row cohort out-performed the column cohort at the $10 \%$ level of significance.

If older cohorts outperform younger cohorts, the ' + ' signs should be found above the diagonal of the matrix in Table 7. We see that this is true of almost all comparisons across cohorts on average. An average member of the 1986 cohort outperforms average members of all subsequent cohorts, the 1990, 1991 and 1992 graduates, on average, consistently outperform graduates from later years, whereas the 1989 graduates outperform only 1997 and 1998 graduates on average. There are only two cases where a younger cohort outperforms an older one: 1991 outperforms 1989, and 1999 outperforms 1997, both at a significance level of $10 \%$. Thus, after controlling for life cycle effects, we reach the following conclusion: there is a significant decrease in Ph.D.s' annual publication productivity from the late 1980s until the mid-1990s. Performance of graduates from 1995 to 2000 cannot be statistically distinguished, except that 1999 statistically significantly outperforms 1997.

As we mentioned above, whether a cohort statistically significantly outperforms another cohort depends on how we measure the annual research productivity. To this end, we run the same procedure as in Table 7 using the other three research productivity measures mentioned above. Tables A.5, A.6, and A.7 in the appendix document pairwise comparisons of cohorts when we use AER-equivalent publications with full credit, AER-equivalent publications with discrete quality ranking, and number of publications without quality adjustment as measures for research productivity, respectively. As Tobit estimates in Table 6 already suggest, different productivity measures yield different, however encompassing results. In all three cases documented in Tables A.5, A.6, and A.7, the ' + ' signs are found almost always above the diagonal of the matrix in the respective table. Hence using different productivity measures doesn't change our basic conclusions from analyzing Table 7: Ph.D.s' annual publication productivity from the late 1980s until the mid-1990s drops significantly, and research productivities of cohorts from 1995 to 2000 cannot be statistically distinguished, except for only a few cases. 
Research productivity differences across cohorts become obvious when we use the number of total publications to measure research productivity, as shown in Table A.7. However we doubt that this is a reliable measure, because quality is an essential part of measuring and evaluating research output. Our other three productivity measures integrate publication quality and thus establish an AER-equivalence for annual research productivity. Comparing these three measures, differences across cohorts are more pronounced when we use the annual number of AER-equivalent publications calculated using a discrete journal ranking. Since journals are grouped into different tiers in this ranking, a shift of publications across tiers would generate a greater, and more importantly, a discontinuous downward shift in research productivity as opposed to what would happen when using a continuous journal ranking. Results shown in Table A.6 reveal that younger cohorts might be publishing significantly less in the top-tier and more in the second-tier or third-tier journals compared to older cohorts. Results shown in Table 7 are based on the annual number of AER-equivalent publications that are calculated using a continuous ranking of journals, and they yield fewer amount of statistically significant productivity differences in the pairwise comparison of cohorts compared to the one using discrete rankings. Finally, when we don't discount for coauthorship and assign each coauthor full credit for a publication while using a continuous ranking, then differences across cohorts become even less pronounced. This is in line with what we have already shown in earlier sections, that younger cohorts tend to coauthor more than older cohorts. This may simply reflect a shift in social norms in the profession, or it may be a strategy to get around the Ellison Effect. Nevertheless it does not seem to work to save younger cohorts from being outperformed by older ones, as shown in Table A.5.

\subsection{Research Productivity within and across Quintiles}

As shown in section 4.1, distribution of research productivity of Ph.D.s is extremely skewed: the top 5\% of Ph.D.s produce about $40 \%$, and the top $20 \%$ of $\mathrm{Ph}$.D.s produce about $80 \%$ of all publications in their respective cohorts. Similar skewedness shows up across all cohorts. Our analysis so far has compared cohorts based on their average performance. The extreme skewedness of productivity distribution within cohorts, however, suggests that comparisons of the output of different productivity percentiles across cohorts would be interesting. To this end, we rank all Ph.D.s within a given cohort based on the number of AER equivalent publications ${ }^{17}$ they achieve at the end of sixth year after graduation. We then compare annual productivity of Ph.D.s across cohorts who are in the third quintile range (between 40th and 60th percentiles), and then those who are in the second quintile range (between 60th and 80th percentiles), and finally those in the top quintile range. We run pooled Tobit estimation with the same specification as above on these three quintile ranges $^{18}$. Marginal effects for the top three quintile ranges are reported in Table 8.

\footnotetext{
${ }^{17}$ These are calculated using continuous journal rankings and assigning equal share to each coauthor.

${ }^{18}$ We determine quintile ranges based on cumulative productivity at the end of sixth year after graduation, because annual productivity is highly volatile. If we look at annual productivity, a highly productive graduate may be found in the lowest quintile range at some years due to this volatility. As a result, determining graduates' productivity quintiles in the above manner and comparing the same quintile range across cohorts using marginal effects from the pooled Tobit regression proves to be a more sensible method than using quantile regression on annual productivity. (See e.g. Koenker (2004)).
} 
Table 8. Marginal Effects for Top Three Quintiles

\begin{tabular}{|c|c|c|c|}
\hline & P40-P60 & P60-P80 & P80-P100 \\
\hline Top30 & -0.0004618 & 0.0003573 & $0.0201221^{* * *}$ \\
\hline \multicolumn{4}{|c|}{ Life cycle effects } \\
\hline$t$ & $0.0075388^{* * *}$ & $0.0230354^{* * *}$ & $0.0923817^{* * *}$ \\
\hline$t^{2}$ & $-0.0014535^{* * *}$ & $-0.0036719^{* *}$ & -0.0106398 \\
\hline$t^{3}$ & $0.0000899^{* *}$ & 0.0001701 & 0.0001321 \\
\hline \multicolumn{4}{|c|}{ Cohort effects } \\
\hline 1986 & $0.0034581^{* * *}$ & $0.0138791^{* * *}$ & $0.1060625^{* * *}$ \\
\hline 1987 & $0.0048398^{* * *}$ & $0.0146142^{* * *}$ & $0.0588261^{* * *}$ \\
\hline 1988 & $0.0039493^{* * *}$ & $0.0113483^{* * *}$ & $0.046402^{* * *}$ \\
\hline 1989 & $0.0015597^{* *}$ & 0,003843 & 0,0173163 \\
\hline 1990 & $0.0026034^{* * *}$ & $0.0064763^{* *}$ & $0.0239718^{* *}$ \\
\hline 1991 & $0.0025138^{* * *}$ & $0.0064635^{* *}$ & $0.0373514^{* * *}$ \\
\hline 1992 & $0.0028776^{* * *}$ & $0.005512^{* *}$ & $0.0287218^{* *}$ \\
\hline 1993 & $0.0016973^{* *}$ & 0,002337 & 0,0104932 \\
\hline 1994 & $0.0024074^{* * *}$ & $0.0073632^{* * *}$ & $0.020059^{* *}$ \\
\hline 1995 & $0.0016029^{* *}$ & 0,0004858 & 0,0065441 \\
\hline 1996 & $0.0022369^{* * *}$ & 0,0033282 & 0,004813 \\
\hline 1997 & 0,0007187 & $-0,0005396$ & $-0,0068057$ \\
\hline 1998 & 0,0002142 & 0,0008649 & $-0,000829$ \\
\hline 1999 & $0.0018777^{* * *}$ & 0,0026219 & $-0,0029431$ \\
\hline
\end{tabular}

* significant at $10 \%$;* significant at $5 \%$;** significant at $1 \%$

Interestingly, the positive impact of having graduated from a top thirty department, which is statistically significant for average members of cohorts (see Table 6), has a statistically significant positive impact only for graduates in the top quintile range. Its marginal effect is insignificant for the second and third quintile ranges. This suggests that lower quality graduates of top places are not significantly different from typical graduates of any Ph.D. program. For all three quintile ranges, we observe that cohort effects yield a decreasing trend as we move from older to younger cohorts. Pairwise comparisons of cohorts for the third, the second and the first quintile ranges are reported in Tables 9, 10, and 11, respectively. 
Table 9. Publication comparisons across cohorts (P40-P60)

\begin{tabular}{|c|c|c|c|c|c|c|c|c|c|c|c|c|c|c|}
\hline & 1987 & 1988 & 1989 & 1990 & 1991 & 1992 & 1993 & 1994 & 1995 & 1996 & 1997 & 1998 & 1999 & 2000 \\
\hline 1986 & & & + & & & & + & & + & & + & + & + & + \\
\hline 1987 & & & + & + & + & + & + & + & + & + & + & + & + & + \\
\hline 1988 & & & + & & & & + & + & + & + & + & + & + & + \\
\hline 1989 & & & & & & & & & & & & + & & + \\
\hline 1990 & & & & & & & & & & & + & + & & + \\
\hline 1991 & & & & & & & & & & & + & + & & + \\
\hline 1992 & & & & & & & & & & & + & + & & + \\
\hline 1993 & & & & & & & & & & & & + & & + \\
\hline 1994 & & & & & & & & & & & + & + & & + \\
\hline 1995 & & & & & & & & & & & & + & & + \\
\hline 1996 & & & & & & & & & & & + & + & & + \\
\hline 1997 & & & & & & & & & & & & & & \\
\hline 1998 & & & & & & & & & & & & & & \\
\hline 1999 & & & & & & & & & & & & & & + \\
\hline
\end{tabular}

Note: A "+" indicates the row cohort out-performed the column cohort at the $5 \%$ level of significance.

Table 10. Publication comparisons across cohorts (P60-P80)

\begin{tabular}{|c|c|c|c|c|c|c|c|c|c|c|c|c|c|c|}
\hline & 1987 & 1988 & 1989 & 1990 & 1991 & 1992 & 1993 & 1994 & 1995 & 1996 & 1997 & 1998 & 1999 & 2000 \\
\hline 1986 & & & + & + & + & + & + & + & + & + & + & + & + & + \\
\hline 1987 & & & + & + & + & + & + & + & + & + & + & + & + & + \\
\hline 1988 & & & + & & & + & + & & + & + & + & + & + & + \\
\hline 1989 & & & & & & & & & & & & & & \\
\hline 1990 & & & & & & & & & + & & + & + & & + \\
\hline 1991 & & & & & & & & & + & & + & + & & + \\
\hline 1992 & & & & & & & & & + & & + & + & & + \\
\hline 1993 & & & & & & & & & & & & & & \\
\hline 1994 & & & & & & & & & + & & + & + & & + \\
\hline 1995 & & & & & & & & & & & & & & \\
\hline 1996 & & & & & & & & & & & & & & \\
\hline 1997 & & & & & & & & & & & & & & \\
\hline 1998 & & & & & & & & & & & & & & \\
\hline 1999 & & & & & & & & & & & & & & \\
\hline
\end{tabular}

Note: A "+" indicates the row cohort out-performed the column cohort at the $5 \%$ level of significance. 
Table 11. Publication comparisons across cohorts (P80-P100)

\begin{tabular}{|c|c|c|c|c|c|c|c|c|c|c|c|c|c|c|}
\hline & 1987 & 1988 & 1989 & 1990 & 1991 & 1992 & 1993 & 1994 & 1995 & 1996 & 1997 & 1998 & 1999 & 2000 \\
\hline 1986 & + & + & + & + & + & + & + & + & + & + & + & + & + & + \\
\hline 1987 & & & + & + & & + & + & + & + & + & + & + & + & + \\
\hline 1988 & & & + & + & & & + & + & + & + & + & + & + & + \\
\hline 1989 & & & & & & & & & & & + & & + & \\
\hline 1990 & & & & & & & & & & + & + & + & + & + \\
\hline 1991 & & & & & & & + & & + & + & + & + & + & + \\
\hline 1992 & & & & & & & & & + & + & + & + & + & + \\
\hline 1993 & & & & & & & & & & & & & & \\
\hline 1994 & & & & & & & & & & & + & + & + & + \\
\hline 1995 & & & & & & & & & & & & & & \\
\hline 1996 & & & & & & & & & & & & & & \\
\hline 1997 & & & & & & & & & & & & & & \\
\hline 1998 & & & & & & & & & & & & & & \\
\hline 1999 & & & & & & & & & & & & & & \\
\hline
\end{tabular}

Note: A "+" indicates the row cohort out-performed the column cohort at the $5 \%$ level of significance.

Although pairwise comparisons of cohorts for the top three quintile ranges yield more or less similar results as pairwise comparison of cohorts' average performers (see Table 7), they do reveal an interesting pattern. Comparing the third quintile ranges across cohorts (see Table 9), we observe that 1986, 1987, and 1988 cohorts outperform most of the younger cohorts, and 1997, 1998, and 2000 cohorts are outperformed by most of the older cohorts. As we move to higher quintile ranges, the upper diagonal of the 'pairwise comparison matrix' displays more ' + ' signs. That is, as we compare higher quintile ranges across cohorts, the dominance of older cohorts over younger cohorts, and the chronological ordering of cohorts in publication productivity become more evident. This means that top performers of each cohort are hit more severely by the publication bottleneck, namely the Ellison Effect. This in turn suggests that the top performers of the youngest generation are likely to fall most short of productivity expectations formed on the basis of this historical publishing environment, while middle and lower performers may not look much different than their predecessors. Top departments especially should be aware of these facts when evaluating junior faculty for tenure.

We plot cohort effects across percentiles in Figure 12, which shows how cohort effect for a given cohort changes across different percentile ranges ${ }^{19}$. Cohort effects are hard to distinguish in lower percentile ranges, especially up to the range of 40th to 50th percentile, and they don't line up following a chronological ordering. There exists, however, a much clearer pattern for higher percentile ranges, and they line up following chronological ordering, except that 1999 cohort's top percentile range performs poorer than that of the 2000 cohort. One should keep in mind that there will necessarily be more variation in productivity of Ph.D.s in higher percentile ranges, because they produce larger amounts of publications than those in lower

\footnotetext{
${ }^{19}$ We group Ph.D.s in each cohort into percentile ranges of ten increments (range of 90th to 100th percentile, range of 80th to 90 th percentile etc) based on their cumulative performance at the end of sixth year after graduation and estimate cohort effects across percentile ranges as we did with quintile ranges. We plot only cohorts 1988, 1991, 1994, and 1999 for illustrative purposes.
} 
percentile ranges. This means that the confidence intervals around cohort effects are also widening as cohort effects diverge in high percentile ranges, so that some of this divergence may be insignificant. Tables 9 to 11 show that although not all of the divergence in cohort effects in high percentile ranges is significant, a considerable amount of it is significant so that the upper diagonal of the 'pairwise comparison matrix' gets filled with more ' + ' signs as we consider higher percentile ranges.

\section{Conclusion}

Ellison (2002) documents how most journals require today more than double the time they required thirty years ago to evaluate a submitted paper. It is only natural to wonder how this longer "time to build" production process for published manuscripts affects younger Ph.D.s.. It is particularly important to investigate whether younger cohorts perform significantly more poorly than older cohorts in terms of research output. Promotions, job offers and tenure decisions in academia are based on an individual's publication record. This publication record is not only compared to his/her cohort peers, but also to older cohorts, because institutions may be worried about keeping their established standards. Assuming that younger cohorts are not less smart or working less diligently than older cohorts, a downward trend in publication records as cohorts get younger must have important policy implications for the economics Ph.D. job market.

Reconstructing the journal publication record of 14,271 graduates from U.S. and Canadian Ph.D.-granting economics departments from 1986 to 2000, we obtain strong evidence of productivity decrease as we compare younger to older cohorts. It is evident that there is a downward shift that begins with sharp declines in the late 1980s and seems to settle into a steady-state pattern in the late 1990s. In the last few years, the annual flow differences across cohorts are too small numerically to be statistically distinguishable. Looking at the cumulative number of AER equivalent publications reached at the end of six years after graduation, we see convincing evidence of the expected productivity decline for both top and non-top thirty departments. Thus, unless we believe that recent graduates are fundamentally of poorer quality, the same quality of tenure candidate is significantly less productive today than 10 or 15 years ago.

If we use the number of AER equivalent pages as a measure of productivity, then the above mentioned drop off in productivity is not obvious. This is consistent with Ellison's (2002) documentation of the increasing length and decreasing number of published papers. This exposes a significant methodological question about the best way to measure productivity of departments, graduate programs and individual scholars. Productivity patterns over time look different depending on whether number of papers or pages is chosen as a basis of comparison. We argue that what the profession values when granting tenure, giving raises, or making senior hires is the number of lines on a CV and the quality of the research papers on those lines. It is much harder to distill this into the number of AER-quality weighted pages, and we suspect that this is seldom attempted in practice. 


\section{References}

[1] Combes, Pierre-Philippe, and Laurent Linnemer. 2003. "Where are the Economists who Publish? Publication Concentration and Rankings in Europe Based on Cumulative Publications." Journal of the European Economic Association, 1(6): 1250-1308.

[2] Combes, Pierre-Philippe, and Laurent Linnemer. 2010. "Inferring Missing Citations, A Quantitative Multi-Criteria Ranking of all Journals in Economics." GREQAM Working Paper, no. 2010-28.

[3] Collins, Jeffery T., Richard G. Cox, and Victor Stango. 2000. "The Publishing Patterns of Recent Economics Ph.D. Recipients." Economic Inquiry, 38(2): 358-367.

[4] Coupe, Tom. 2003. "Revealed Performances: Worldwide Rankings of Economists and Economics Departments, 1990-2000." Journal of the European Economic Association, 1: 1309-1345.

[5] Davis, Joe C., and Debra Moore Patterson. 2001. "Determinants of Variations in Journal Publication Rates of Economists." The American Economist, 45(1): 86-91.

[6] Ellison, Glenn. 2002. "The Slowdown of the Economics Publishing Process." Journal of Political Economy, 110(5): 947-993.

[7] Fafchamps, Marcel, Marco J. van der Leij, and Sanjeev Goyal. 2006. "Scientific Networks And Co-Authorship." University of Oxford Economics Discussion Paper no.256.

[8] Goodwin, Thomas H., and Raymond D. Sauer. 1995. "Life Cycle Productivity in Academic Research: Evidence from Cumulative Publications Histories of Academic Economists." Southern Economics Journal, 61: 728-743.

[9] Goyal, Sanjeev, Marco J. van der Leij, and José Luis Moraga-Gonzalez. 2006. "Economics: An Emerging Small World." Journal of Political Economy, 114(2): 403-432.

[10] Hutchinson, E. Bruce, and Terry L. Zivney. 1995. "The Publication Profile of Economists." Journal of Economic Education, 26(1): 59-79.

[11] Kalaitzidakis, Pantelis, Theofanis P. Mamuneas, and Thanasis Stengos. 2003. "Rankings of Academic Journals and Institutions in Economics." Journal of the European Economic Association, 1(6): 1346-1366.

[12] Koenker, Roger. 2004. "Quantile Regression for Longitudinal Data." Journal of Multivariate Analysis, 91: 74-89.

[13] Levin, Sharon G., and Paula E. Stephan. 1991. "Research Productivity Over the Life Cycle: Evidence for Academic Scientists." American Economic Review, 81(1): 114-131.

[14] Rauber, Michael, and Heinrich W. Ursprung. 2008. "Life Cycle and Cohort Productivity in Economic Research: The Case of Germany." German Economic Review, 9(1): 431-456.

[15] Stock, Wendy A., T. Aldrich Finegan, and John J. Siegfried. 2009. "Completing an Economics Ph.D. in Five Years." American Economic Review, 99(2): 624-629. 
[16] Stock, Wendy A., and John J. Siegfried. 2006. "Where Are They Now? Tracking the Ph.D. Class of 1997." Southern Economic Journal, 73(2): 472-488.

[17] Stock, Wendy A., and John J. Siegfried. 2006. "Time-to-Degree for the Economics Ph.D. Class of 2001-2002." American Economic Review, 96(2): 467-474. 


\section{Appendix}

Table A.1. Number of Ph.D.s in Economics by Data Source

\begin{tabular}{rrrrr}
\hline \hline Year & AEA & Hasselback & Overlap & \multicolumn{1}{c}{ Total } \\
\hline 1986 & 264 & 227 & 61 & 425 \\
1987 & 597 & 216 & 95 & 714 \\
1988 & 787 & 196 & 94 & 883 \\
1989 & 953 & 230 & 147 & 1,035 \\
1990 & 947 & 164 & 107 & 1,001 \\
1991 & 905 & 178 & 122 & 956 \\
1992 & 928 & 155 & 106 & 970 \\
1993 & 1,074 & 173 & 110 & 1,132 \\
1994 & 1,021 & 182 & 122 & 1,077 \\
1995 & 1,025 & 170 & 109 & 1,078 \\
1996 & 955 & 155 & 104 & 1,002 \\
1997 & 935 & 167 & 107 & 990 \\
1998 & 981 & 178 & 113 & 1,040 \\
1999 & 866 & 182 & 106 & 936 \\
2000 & 969 & 181 & 110 & 1,032 \\
\hline
\end{tabular}

Note: The overlap indicates the number of PhDs common to the AEA and Hasselback data. 
Table A.2. Number of Publications

\begin{tabular}{cc}
\hline \hline Year & Number \\
\hline 1985 & 9,918 \\
1986 & 9,872 \\
1987 & 9,918 \\
1988 & 10,552 \\
1989 & 10,767 \\
1990 & 11,254 \\
1991 & 11,905 \\
1992 & 13,108 \\
1993 & 13,492 \\
1994 & 14,374 \\
1995 & 15,825 \\
1996 & 17,692 \\
1997 & 18,385 \\
1998 & 19,869 \\
1999 & 20,818 \\
2000 & 21,835 \\
2001 & 22,271 \\
2002 & 21,991 \\
2003 & 23,510 \\
2004 & 25,618 \\
2005 & 25,976 \\
2006 & 19,722 \\
\hline
\end{tabular}


Table A.3. Journal Weights Relative to the American Economic Review

\begin{tabular}{|c|c|c|c|}
\hline Journal & Index & Journal & Index \\
\hline 1. American Economic Review & 1.000 & 36. IJGT & 0.061 \\
\hline 2. Econometrica & 0.968 & 37. Economic Inquiry & 0.060 \\
\hline 3. Journal of Political Economy & 0.652 & 38. World Bank Economic Review & 0.057 \\
\hline 4. Journal of Economic Theory & 0.588 & 39. Journal of Risk and Uncertainty & 0.056 \\
\hline 5. Quarterly Journal of Economics & 0.581 & 40. Journal of Development Economics & 0.055 \\
\hline 6. Journal of Econometrics & 0.549 & 41. Land Economics & 0.051 \\
\hline 7. Econometric Theory & 0.459 & 42. IMF Staff Papers & 0.051 \\
\hline 8. Review of Economic Studies & 0.452 & 43. Canadian Journal of Economics & 0.051 \\
\hline 9. JBES & 0.384 & 44. Public Choice & 0.050 \\
\hline 10. Journal of Monetary Economics & 0.364 & 45. Theory and Decision & 0.049 \\
\hline 11. Games and Economic Behavior & 0.355 & 46. Economica & 0.046 \\
\hline 12. Journal of Economic Perspectives & 0.343 & 47. Journal of Urban Economics & 0.044 \\
\hline 13. Review of Economics and Statistics & 0.280 & 48. IJIO & 0.043 \\
\hline 14. European Economic Review & 0.238 & 49. JLEO & 0.041 \\
\hline 15. JEEA & 0.238 & 50. Journal of Law and Economics & 0.039 \\
\hline 16. International Economic Review & 0.230 & 51. National Tax Journal & 0.039 \\
\hline 17. Economic Theory & 0.224 & 52. Journal of Industrial Economics & 0.039 \\
\hline 18. Journal of Human Resources & 0.213 & 53. Journal of Economic History & 0.038 \\
\hline 19. Economic Journal & 0.207 & 54. Oxford Economic Papers & 0.037 \\
\hline 20. Journal of Public Economics & 0.198 & 55. Journal of Comparative Economics & 0.034 \\
\hline 21. Journal of Economic Literature & 0.188 & 56. World Development & 0.032 \\
\hline 22. Economics Letters & 0.187 & 57. Southern Economic Journal & 0.031 \\
\hline 23. Journal of Applied Econometrics & 0.166 & 58. Explorations in Economic History & 0.030 \\
\hline 24. JEDC & 0.145 & 59. Economic Record & 0.029 \\
\hline 25. Journal of Labor Economics & 0.128 & 60. Journal of Banking and Finance & 0.026 \\
\hline 26. JEEM & 0.119 & 61. Contemporary Economic Policy & 0.024 \\
\hline 27. RAND Journal of Economics & 0.114 & 62. Journal of Population Economics & 0.024 \\
\hline 28. Scandinavian Journal of Economics & 0.107 & 63. JFQA & 0.021 \\
\hline 29. Journal of Financial Economics & 0.099 & 64. JITE & 0.020 \\
\hline 30 OBES & 0.084 & 65. Applied Economics & 0.020 \\
\hline 31. Journal of International Economics & 0.078 & & \\
\hline 32. Journal of Mathematical Economics & 0.076 & & \\
\hline 33. JEBO & 0.071 & & \\
\hline 34. Social Choice and Welfare & 0.069 & & \\
\hline 35. AJAE & 0.062 & & \\
\hline
\end{tabular}

Note: Journal of Business and Economic Statistics (JBES), Journal of the European Economic Association (JEEA), Journal of Environmental Economics and Management (JEEM), Oxford Bulletin of Economics and Statistics (OBES), Journal of Economic Behavior and Organization (JEBO) American Journal of Agricultural Economics (AJAE,), International Journal of Game Theory (IJGT) International Journal of Industrial Organization (IJIO) ,Journal of Law, Economics, and Organization (JLEO), Journal of Financial and Quantitative Analysis (JFQA), Journal of Institutional and Theoretical Economics (JITE) 
Table A.4. Top Thirty Economics Departments in US and Canada

\begin{tabular}{|c|c|c|c|}
\hline Rank & Ordered by faculty productivity & Ordered by productivity of Ph.D.s & Index* \\
\hline 1. & Harvard University & MIT & 0,801 \\
\hline 2. & University of Chicago & Princeton University & 0,741 \\
\hline 3. & University of Pennsylvania & Harvard University & 0,694 \\
\hline 4. & Stanford University & University of Rochester & 0,674 \\
\hline 5 . & MIT & California Institute of Technology & 0,602 \\
\hline 6. & UC-Berkeley & Yale University & 0,596 \\
\hline 7. & Northwestern University & Northwestern University & 0,578 \\
\hline 8. & Yale University & Carnegie Mellon University & 0,544 \\
\hline 9. & University of Michigan & University of Chicago & 0,522 \\
\hline 10. & Columbia University & UC-San Diego & 0,502 \\
\hline 11. & Princeton University & University of Pennsylvania & 0,487 \\
\hline 12. & UCLA & Stanford University & 0,477 \\
\hline 13. & New York University & University of Toronto & 0,421 \\
\hline 14. & Cornell University & University of Western Ontario & 0,401 \\
\hline 15. & University of Wisconsin & University of Minnesota & 0,3842 \\
\hline 16. & Duke University & Brown University & 0,3841 \\
\hline 17. & Ohio State University & University of British Columbia & 0,354 \\
\hline 18. & University of Maryland & Columbia University & 0,353 \\
\hline 19. & University of Rochester & SUNY, Stony Brook & 0,329 \\
\hline 20. & University of Texas, Austin & UCLA & 0,323 \\
\hline 21. & University of Minnesota & University of Iowa & 0,317 \\
\hline 22. & University of Illinois & UC-Berkeley & 0,316 \\
\hline 23. & UC-Davis & University of Virginia & 0,296 \\
\hline 24. & University of Toronto & Duke University & 0,290 \\
\hline 25. & University of British Columbia & Queen's University & 0,271 \\
\hline 26. & UC-San Diego & University of Wisconsin & 0,270 \\
\hline 27. & University of Southern California & University of Michigan & 0,265 \\
\hline 28. & Boston University & Johns Hopkins University & 0,262 \\
\hline 29. & Pennsylvania State University & New York University & 0,260 \\
\hline 30. & Carnegie Mellon University & McMaster University & 0,251 \\
\hline
\end{tabular}

Note: Departments that are ranked top-30 in ONLY one of the two rankings are in italics.

*Index is the average value of AER equivalent publications per research-active graduates at the end of six years after graduation. 
Table A.5. Comparison across Cohorts: AER-Equivalent Publications with Full Credit

\begin{tabular}{|c|c|c|c|c|c|c|c|c|c|c|c|c|c|c|}
\hline & $\begin{array}{c}1987\end{array}$ & 1988 & $\begin{array}{l}1989\end{array}$ & " 1990 & 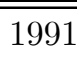 & $\begin{array}{ll}1992\end{array}$ & $\begin{array}{ll}1993 \\
\end{array}$ & 1994 & 19995 & " 1996 & $\begin{array}{l}1997\end{array}$ & $\begin{array}{l}1998 \\
\end{array}$ & 1999 & 2000 \\
\hline 1986 & + & + & + & + & + & + & + & + & + & + & + & + & + & + \\
\hline 1987 & & & + & + & + & + & + & + & + & + & + & + & + & + \\
\hline 1988 & & & + & $(+)$ & & $(+)$ & + & + & + & + & + & + & + & + \\
\hline 1989 & & & & & & & & & & & + & & & \\
\hline 1990 & & & & & & & & & $(+)$ & $(+)$ & + & + & & \\
\hline 1991 & & & $(+)$ & & & & + & $(+)$ & + & + & + & + & + & + \\
\hline 1992 & & & & & & & & & + & $(+)$ & + & + & & \\
\hline 1993 & & & & & & & & & & & $(+)$ & & & \\
\hline 1994 & & & & & & & & & & & + & & & \\
\hline 1995 & & & & & & & & & & & & & & \\
\hline 1996 & & & & & & & & & & & & & & \\
\hline 1997 & & & & & & & & & & & & & & \\
\hline 1998 & & & & & & & & & & & & & & \\
\hline 1999 & & & & & & & & & & & $(+)$ & & & \\
\hline
\end{tabular}

Note: "+" indicates the row cohort out-performed the column cohort at the $5 \%$ level of significance, and "(+)" indicates the row cohort out-performed the column cohort at the $10 \%$ level of significance.

Table A.6. Comparison across Cohorts: AER-Equivalent Publications (Discrete Quality Ranking)

\begin{tabular}{|c|c|c|c|c|c|c|c|c|c|c|c|c|c|c|}
\hline & 1987 & 1988 & 1989 & 1990 & 1991 & 1992 & 1993 & 1994 & 1995 & 1996 & 1997 & 1998 & 1999 & 2000 \\
\hline 1986 & & + & + & + & + & + & + & + & + & + & + & + & + & + \\
\hline 1987 & & & + & + & + & + & + & + & + & + & + & + & + & + \\
\hline 1988 & & & + & $(+)$ & & + & + & + & + & + & + & + & + & + \\
\hline 1989 & & & & & & & & & & & + & + & & + \\
\hline 1990 & & & & & & & $(+)$ & & + & + & + & + & + & + \\
\hline 1991 & & & $(+)$ & & & & + & & + & + & + & + & + & + \\
\hline 1992 & & & & & & & & & + & + & + & + & & + \\
\hline 1993 & & & & & & & & & & & + & + & & + \\
\hline 1994 & & & & & & & & & + & & + & + & & + \\
\hline 1995 & & & & & & & & & & & & & & \\
\hline 1996 & & & & & & & & & & & & & & \\
\hline 1997 & & & & & & & & & & & & & & \\
\hline 1998 & & & & & & & & & & & & & & \\
\hline 1999 & & & & & & & & & & & $(+)$ & & & + \\
\hline
\end{tabular}

Note: "+" indicates the row cohort out-performed the column cohort at the $5 \%$ level of significance, and "(+)" indicates the row cohort out-performed the column cohort at the $10 \%$ level of significance. 
Table A.7. Comparison across Cohorts: Number of Publications (Equal Credit without Quality Weights)

\begin{tabular}{|c|c|c|c|c|c|c|c|c|c|c|c|c|c|c|}
\hline & 1987 & 1988 & 1989 & 1990 & 1991 & 1992 & 1993 & 1994 & 1995 & 1996 & 1997 & 1998 & 1999 & 2000 \\
\hline 1986 & & & + & + & + & + & + & + & + & + & + & + & + & + \\
\hline 1987 & & & + & $(+)$ & & + & + & + & + & + & + & + & + & + \\
\hline 1988 & & & + & & & & + & + & + & + & + & + & + & + \\
\hline 1989 & & & & & & & & & & & + & + & & + \\
\hline 1990 & & & $(+)$ & & & & & & + & + & + & + & + & + \\
\hline 1991 & & & $(+)$ & & & & $(+)$ & & + & + & + & + & + & + \\
\hline 1992 & & & & & & & & & + & + & + & + & $(+)$ & + \\
\hline 1993 & & & & & & & & & & & + & + & & + \\
\hline 1994 & & & & & & & & & + & & + & + & & + \\
\hline 1995 & & & & & & & & & & & & & & $(+)$ \\
\hline 1996 & & & & & & & & & & & $(+)$ & & & + \\
\hline 1997 & & & & & & & & & & & & & & \\
\hline 1998 & & & & & & & & & & & & & & \\
\hline 1999 & & & & & & & & & & & $(+)$ & & & + \\
\hline
\end{tabular}

Note: "+" indicates the row cohort out-performed the column cohort at the $5 \%$ level of significance, and "(+)" indicates the row cohort out-performed the column cohort at the $10 \%$ level of significance. 


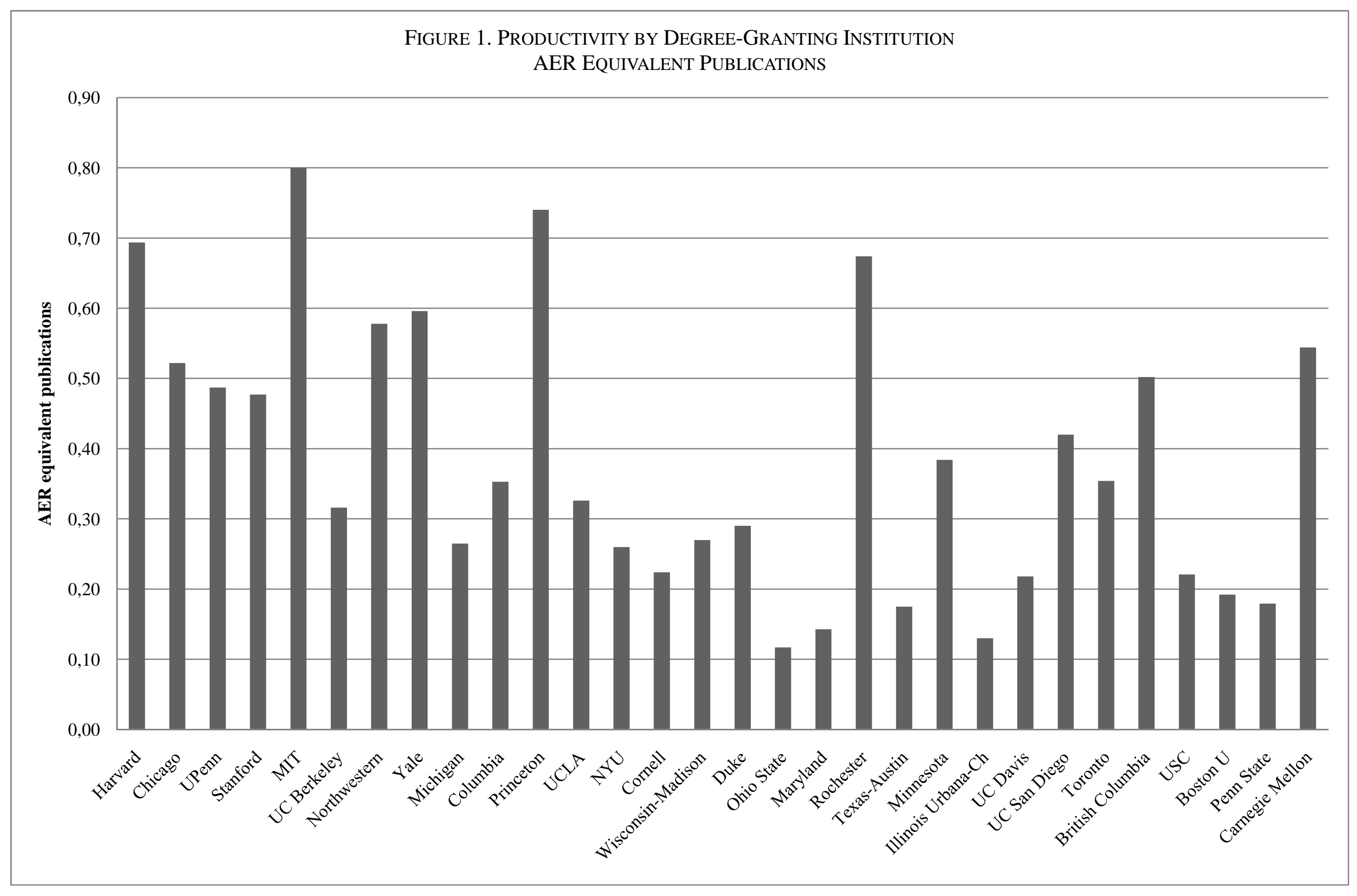


Figure 2. Life-Cycle Productivity of Graduates of ToP 30 Programs ANNUAL RAW PAgES

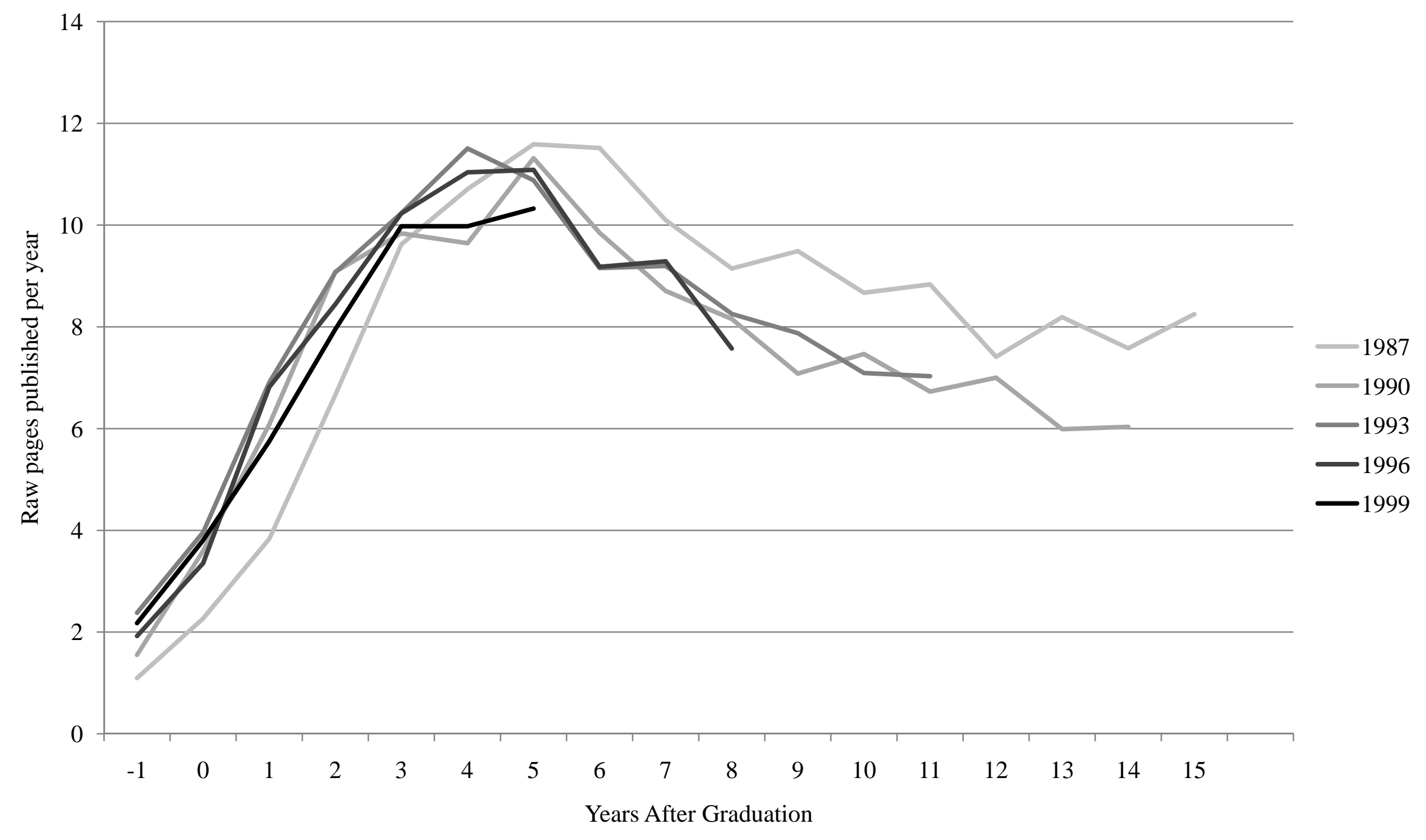


Figure 3. Life-CyCle Productivity of GraduATES OF NON-TOP 30 Programs RAW ANNUAL PAGES

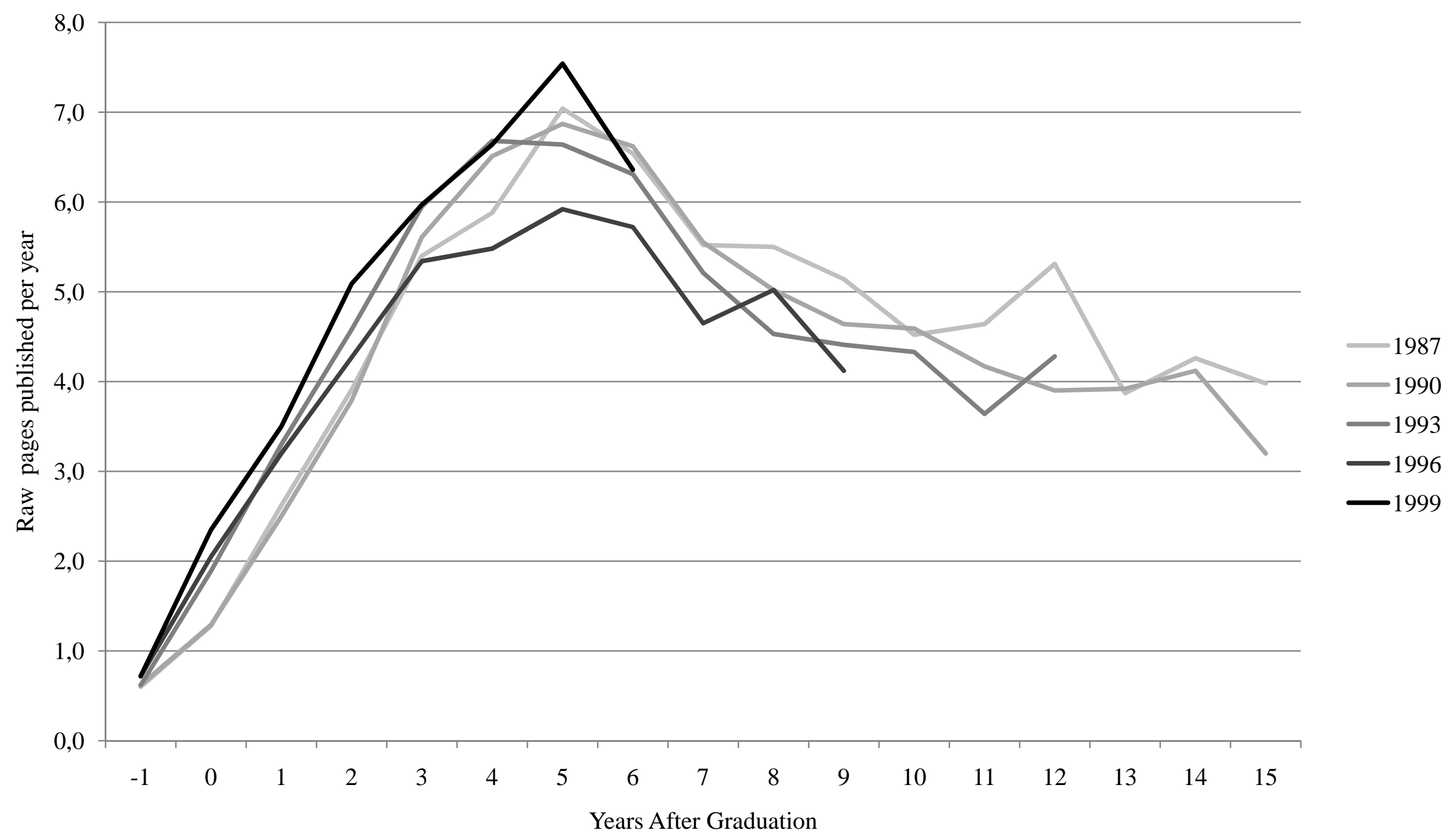


Figure 4. Life-Cycle Productivity of Graduates of tOP 30 Programs RAW ANNUAL PUBLICATIONS

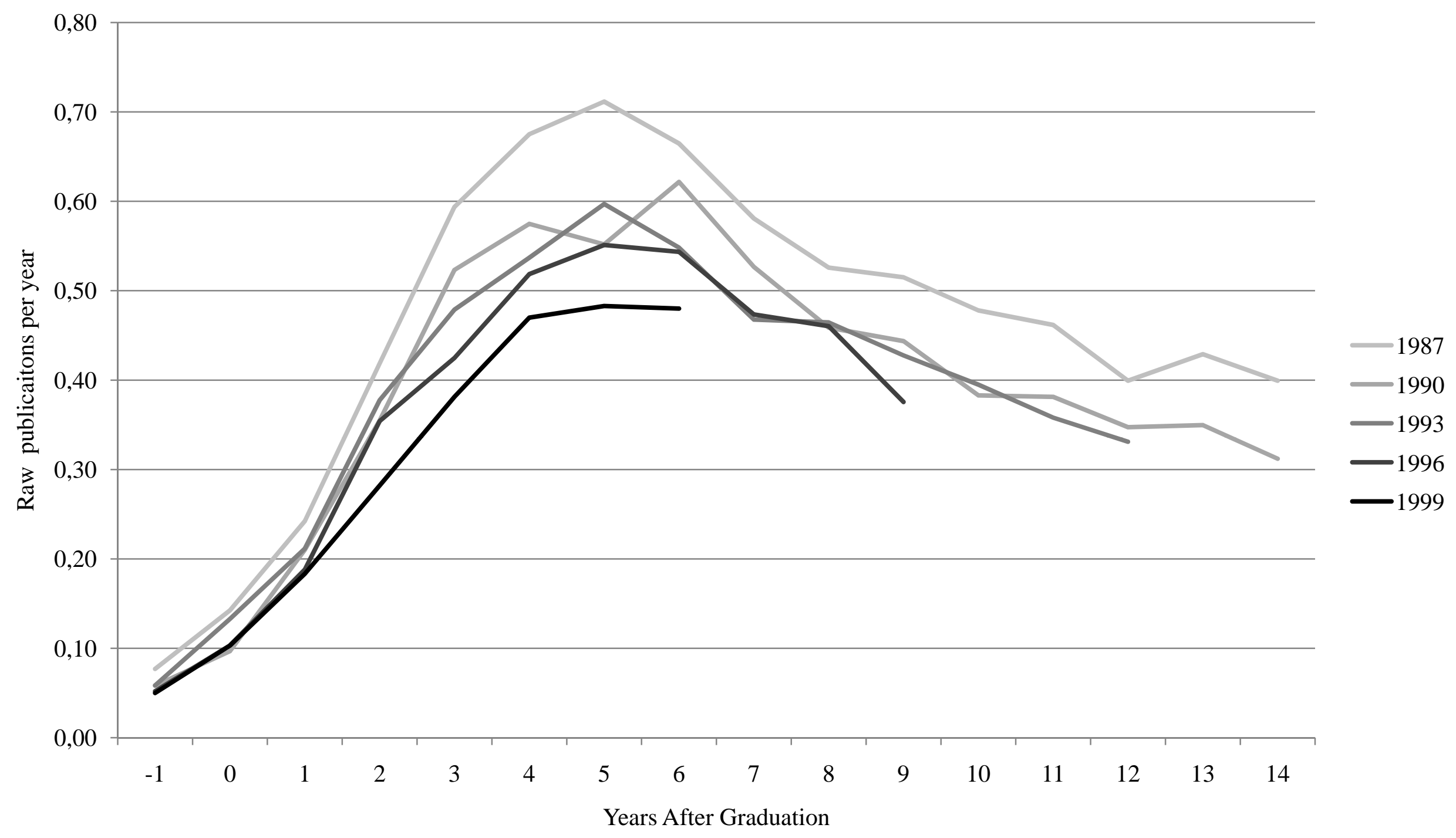


Figure 5. Life-cycle Productivity of Graduates of ToP 30 PROGRAMS AER EQUIVALENT PAGES

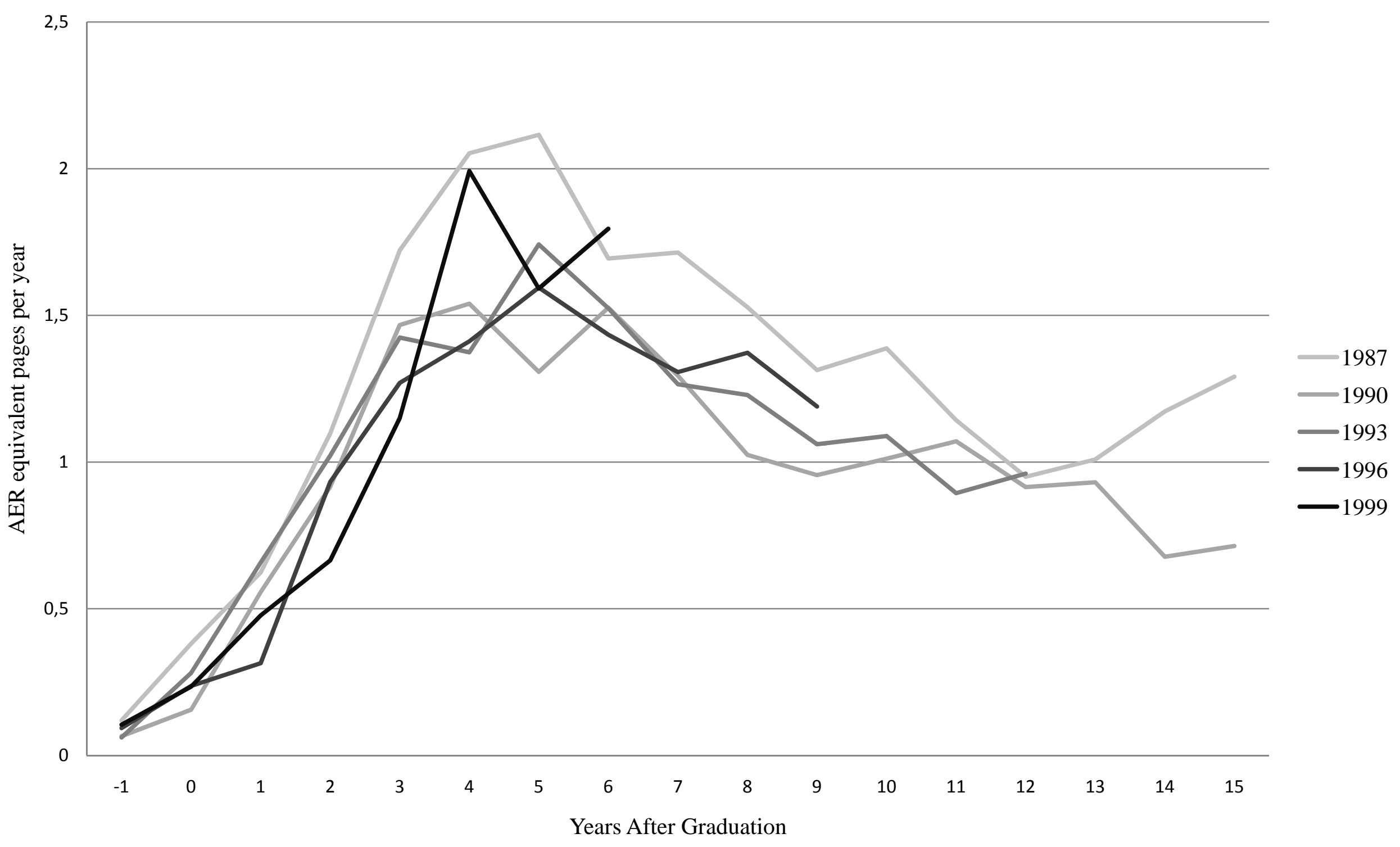


Figure 6. Life-Cycle Productivity of Graduates of top 30 Programs AER EQUIVALENT PAGES BASED ON DISCRETE QUALITY INDEX

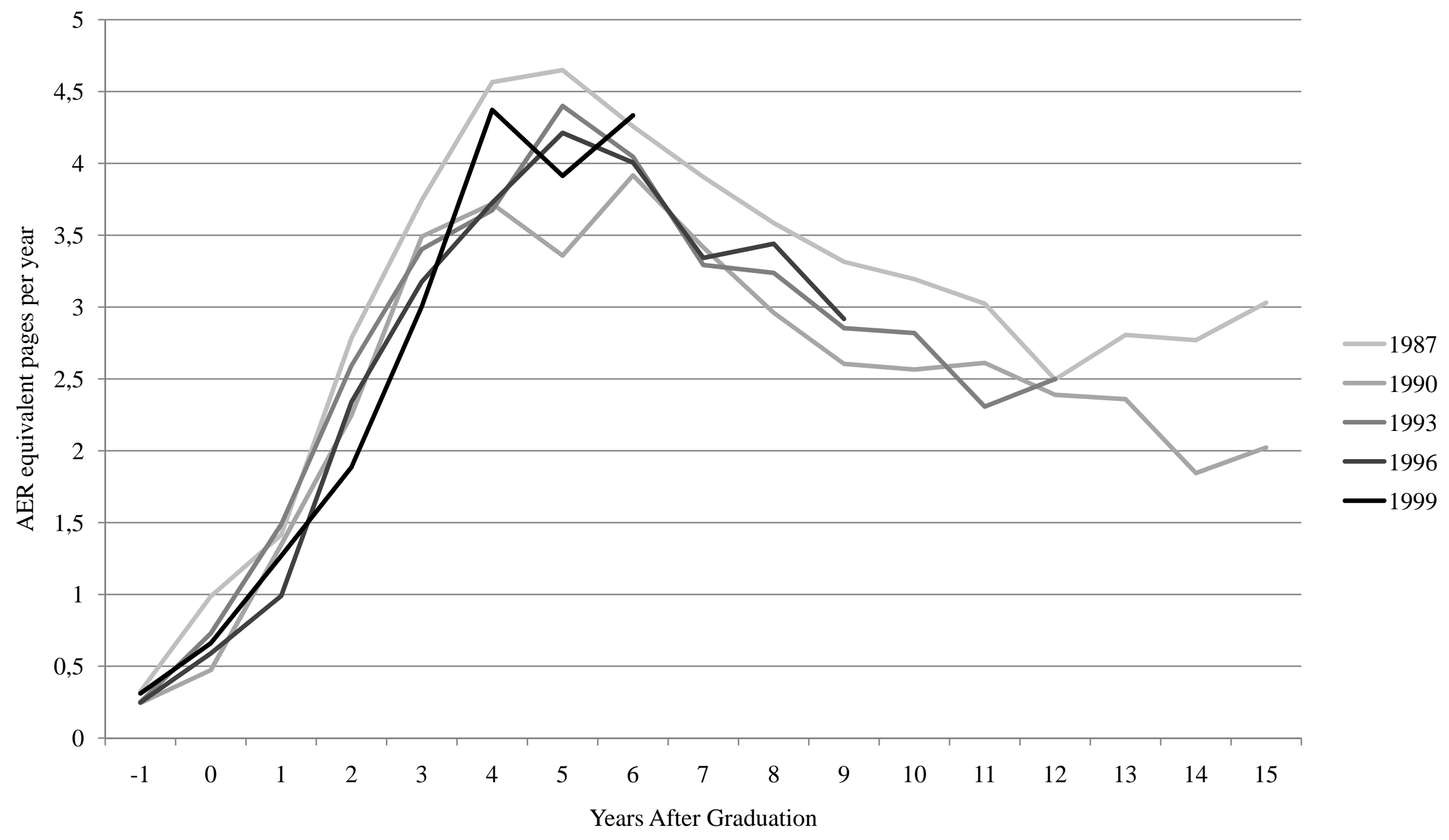


FIGURE 7: COAUTHORSHIP IN ECONLIT JOURNALS

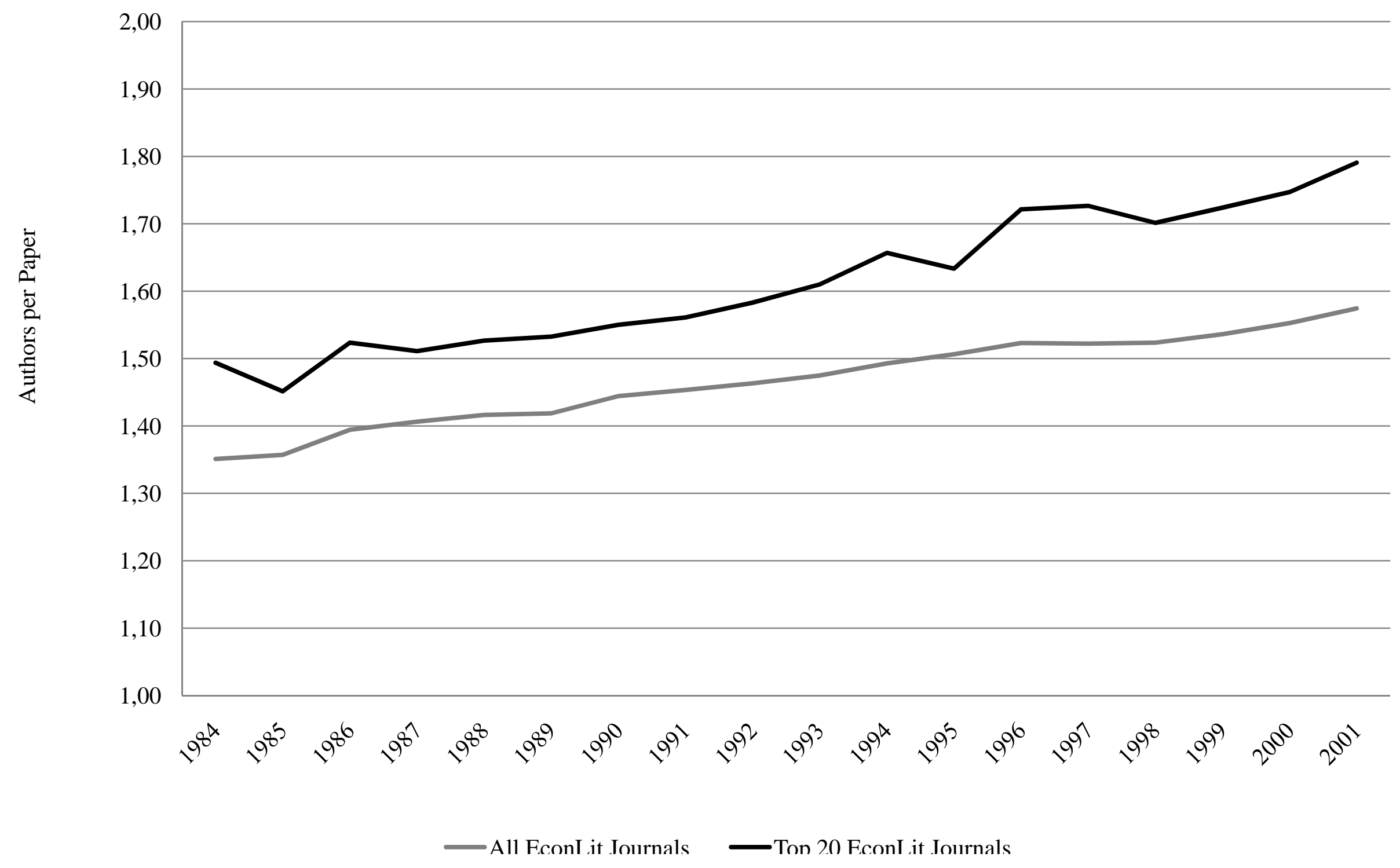


FIGURE 8. LIFE-CYCLE PATTERN OF COAUTHORSHIP

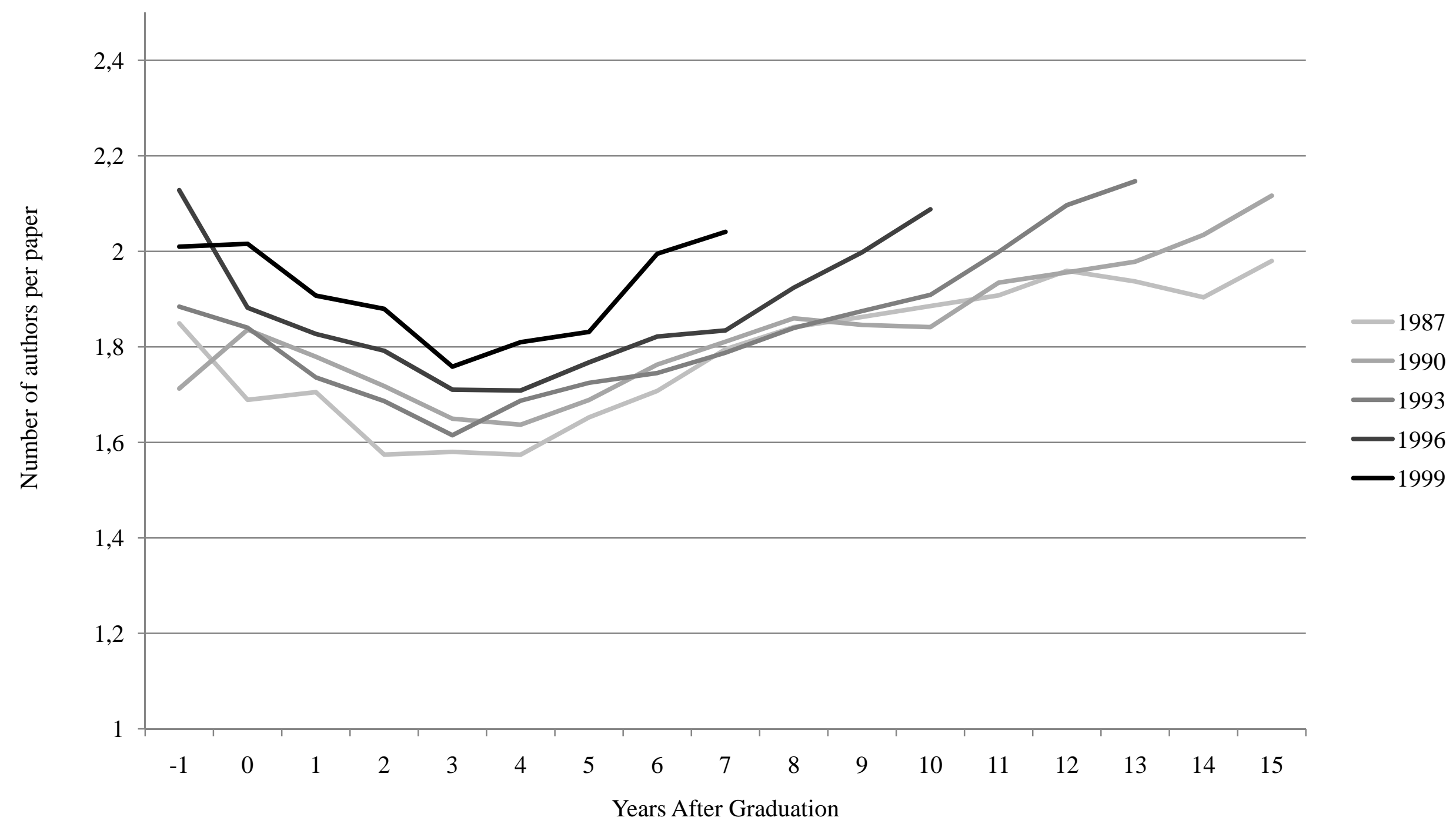




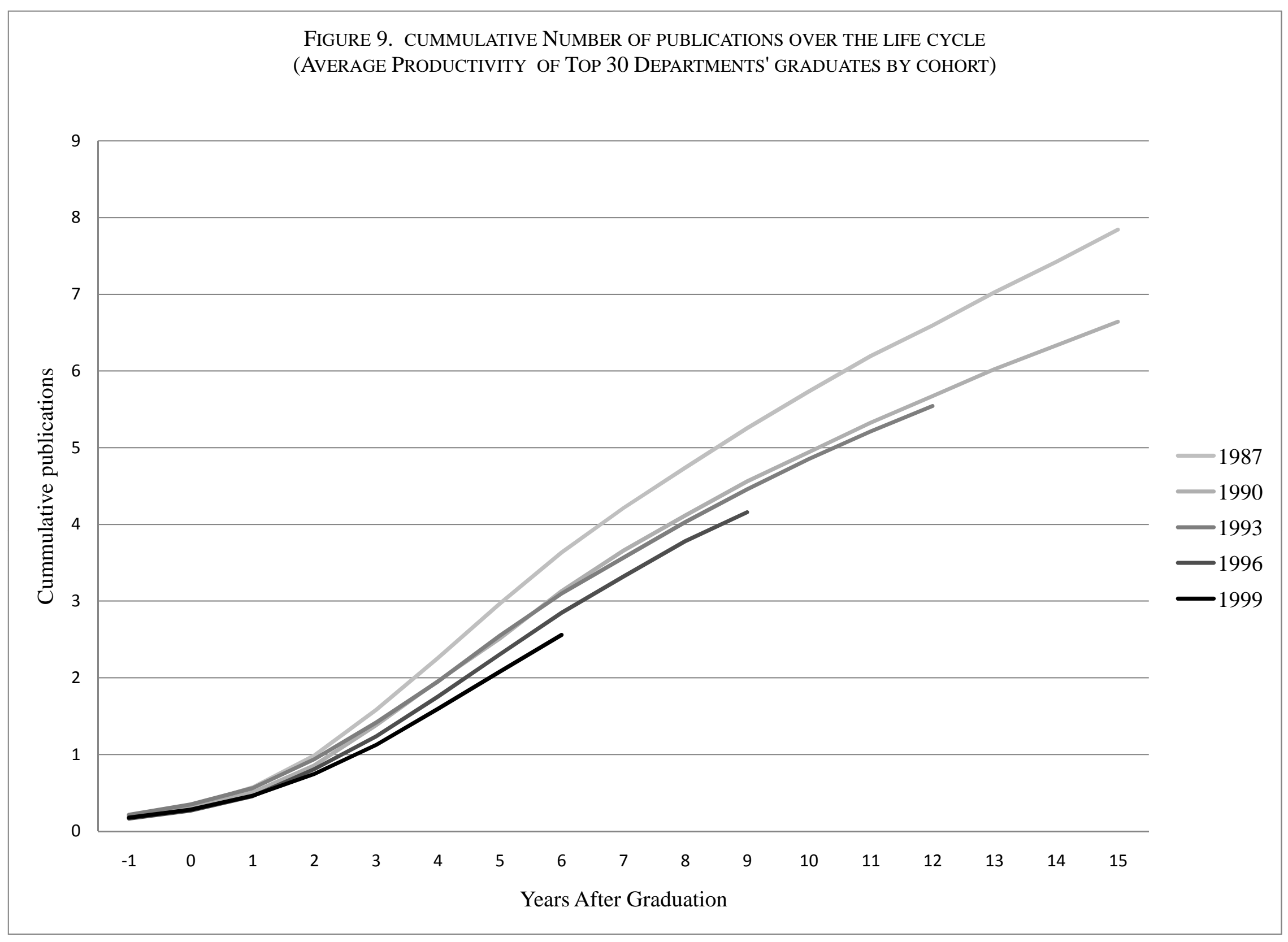


FIGURE 10. CUMMULATIVE AER EQUIVALENT PUBLICATIONS OVER THE LIFE CYCLE

(AVERAgE PRODUCTIVITY OF TOP 30 DEPARTMENTS' GRADUATES BY COHORT)

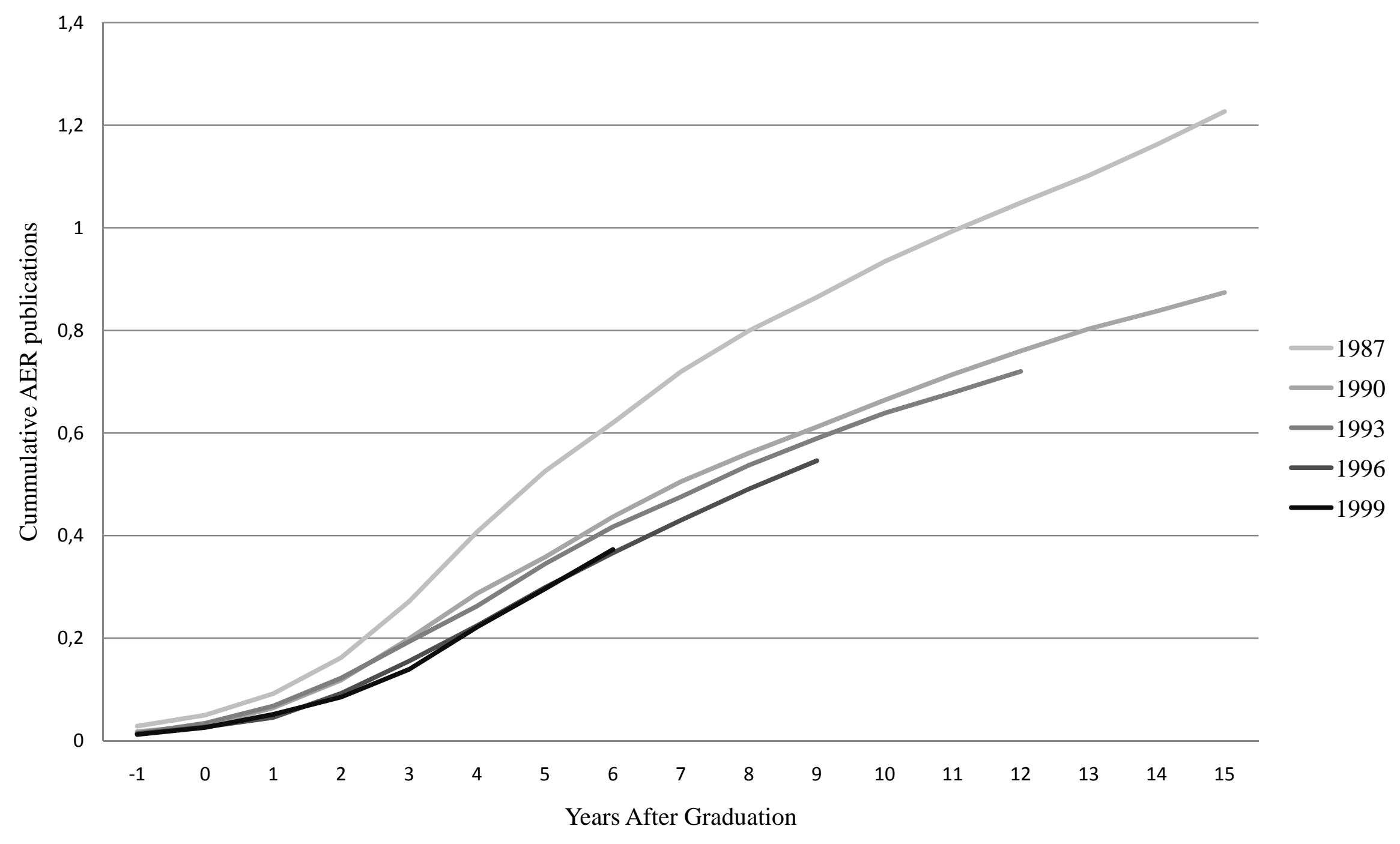




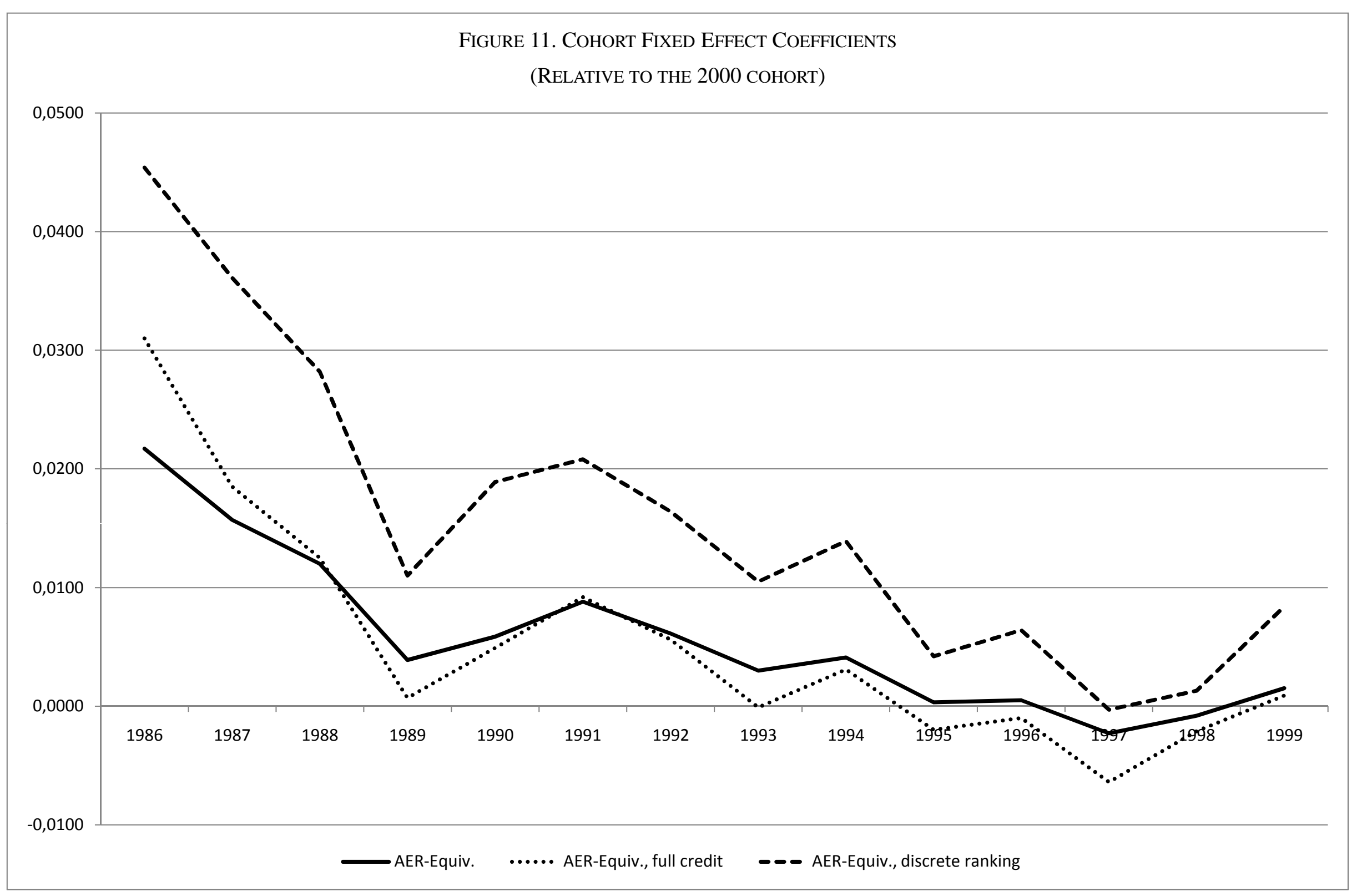




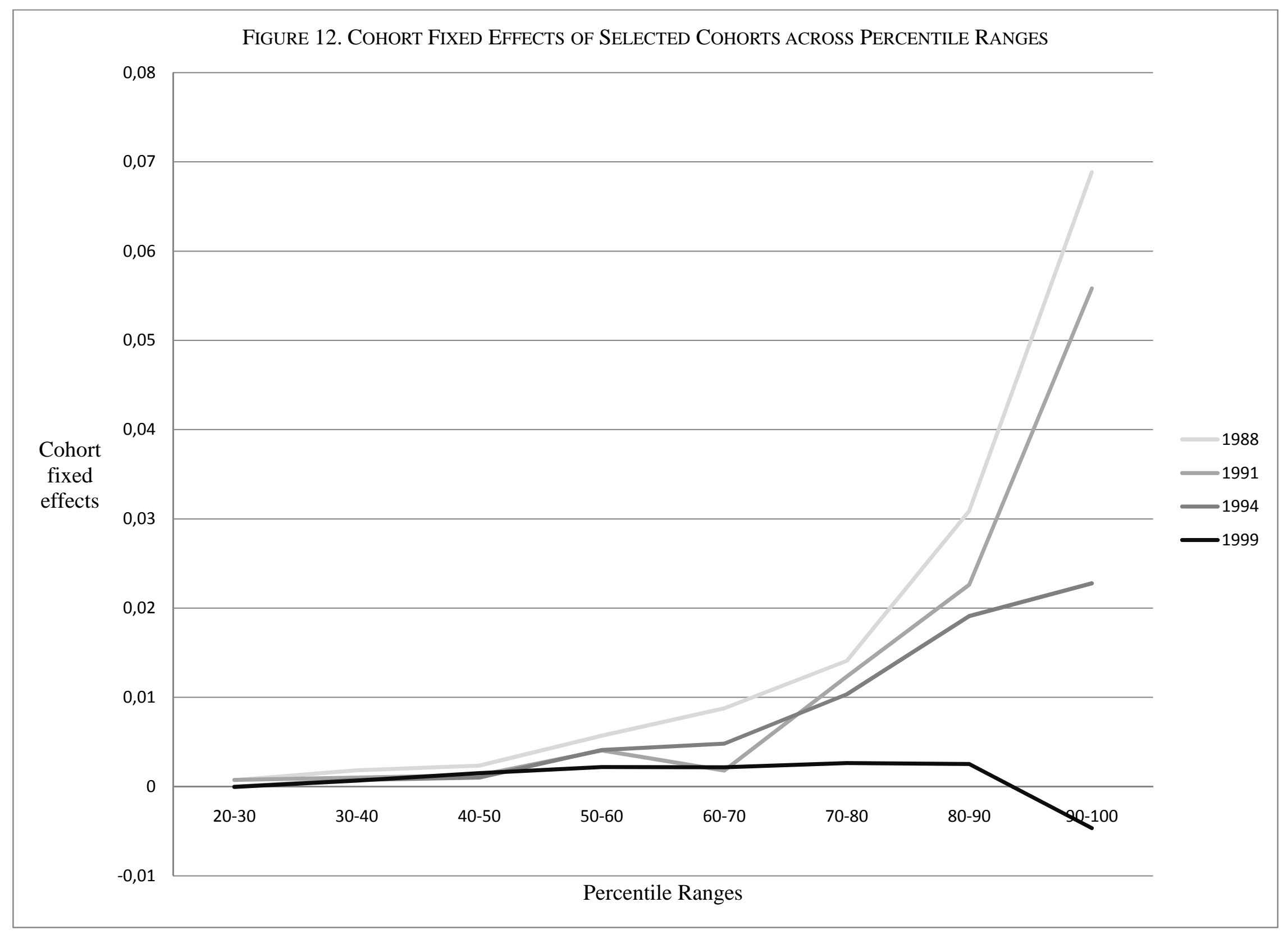

